Article

\title{
Hybrid Molecules Composed of 2,4-Diamino-1,3,5-triazines and 2-Imino-Coumarins and Coumarins. Synthesis and Cytotoxic Properties
}

\author{
Anna Makowska ${ }^{1}$, Franciszek Sączewski ${ }^{1, *}$, Patrick J. Bednarski ${ }^{2}$, Jarosław Sączewski ${ }^{3}$ \\ and Łukasz Balewski ${ }^{1}$ \\ 1 Department of Chemical Technology of Drugs, Faculty of Pharmacy, Medical University of Gdańsk, \\ 80-416 Gdańsk, Poland; an.makow@wp.pl (A.M.); lbalewski@gumed.edu.pl (Ł.B.) \\ 2 Department of Pharmaceutical and Medicinal Chemistry, Institute of Pharmacy, University of Greifswald, \\ L.-F.-Jahn Str., D-17489 Greifswald, Germany; bednarsk@uni-greifswald.de \\ 3 Department of Organic Chemistry, Faculty of Pharmacy, Medical University of Gdańsk, \\ 80-416 Gdańsk, Poland; js@gumed.edu.pl \\ * Correspondence: saczew@gumed.edu.pl; Tel.: +48-58-349-1951; Fax: +48-58-349-1654
}

Received: 31 May 2018; Accepted: 2 July 2018; Published: 3 July 2018

\begin{abstract}
A series of 2-imino-2H-chromen-3-yl-1,3,5-triazine compounds 5-12, which are namely hybrids of 2,4-diamino-1,3,5-triazines and 2-imino-coumarins, was synthesized by reacting 2-(4,6-diamine-1,3,5-triazin-2-yl)acetonitriles 1-4 with 2-hydroxybenzaldehydes. After this, upon heating in aqueous DMF, 2-imino-2H-chromen-3-yl-1,3,5-triazines 10 and 12 were converted into the corresponding $2 H$-chromen-3-yl-1,3,5-triazines 13 and 14, which are essentially hybrids of 2,4-diamino-1,3,5-triazines and coumarins. The in vitro anticancer activity of the newly prepared compounds was evaluated against five human cancer cell lines: DAN-G, A-427, LCLC-103H, SISO and RT-4. The greatest cytotoxic activity displayed 4-[7-(diethylamino)-2-imino-2H-chromen-3-yl]-6-(4-phenylpiperazin-1-yl)-1,3,5-triazin-2-amine $\left(11, \mathrm{IC}_{50}\right.$ in the range of $\left.1.51-2.60 \mu \mathrm{M}\right)$.
\end{abstract}

Keywords: 2-imino-2H-chromen-3-yl-1,3,5-triazines; $2 \mathrm{H}$-chromen-3-yl-1,3,5-triazines; 2,4-diamino1,3,5-triazines; 2-imino-coumarins; coumarins; hybrid molecules; in vitro anticancer activity

\section{Introduction}

It is a well-established fact that numerous medical disorders may be caused by defects in more than one specific biological target, such as a receptor and an enzyme. These disease states cannot be adequately addressed by the classical 'one target, one molecule' approach [1-3]. A promising strategy to tackle complex multifactorial diseases involves the design of hybrid molecules as a stable chemical combination of two drug molecules acting at different targets [4-16]. Such "dual-acting compounds" combine two distinct chemical entities.

The 1,3,5-triazine moiety represents an extraordinary fragment in several promising classes of compounds with an interesting pharmacological profile [17,18]. Since the 1,3,5-triazine scaffold is present in anticancer drugs, such as altretamine [19], trimelamol [20] and irsogladine [21], a considerable amount of attention has recently been paid to the 1,3,5-triazine derivatives with anticancer activity [22-26]. Thus, 1,3,5-triazines derivatives were identified as apoptosis inductors [27] due to being potent inhibitors of telomerase activity, which is associated with cell proliferation [28] and microtubule-binding agents [28-30]. In addition, 1,3,5-triazines with a well-defined antitumor mechanism of action include inhibitors of VEGF-R2 receptor tyrosine kinase [31], tyrosine kinase Tie-2 (tyrosine kinase with immunoglobulin-like and epidermal growth factor-like domains) [32], 
cyclin-dependent kinase [33] and protein kinase CK2 [34], whereas sulfonamides incorporating the 1,3,5-triazine moiety may act as effective carbonic anhydrase inhibitors [35-37].

The coumarin nucleus is a recurring motif in both natural and synthetic compounds of biological interest [38-42], including antiproliferative and cytotoxic agents [43-45]. Thus, novobiocin analogues containing a coumarin scaffold were found to inhibit DNA gyrase in breast cancer cells [46], while a number of coumarin derivatives act as inductors of apoptosis $[47,48]$, protein kinase and mitogen-activated protein kinase inhibitors [49,50]; inhibitors of $17 \beta$-hydroxysteroid dehydrogenase with therapeutic potential in the treatment of hormone-dependent cancers [51]; and inhibitors of several cancer-related isoforms of carbonic anhydrase [52,53]. It was further demonstrated that coumarin-containing compounds suppress microtubule dynamics, effectively blocking cell cycle progression and resulting in apoptosis [54-56], and inhibit angiogenesis. Thus, they represent suitable candidates for the treatment of solid tumors [57]. It should be noted that antitumor activity also exhibit variously substituted imino-icoumarins [58-62].

In previous studies, we have synthesized a number of 1,3,5-triazine derivatives with pronounced in vitro antitumor properties [63-66]. Based on the ideas presented above, we reasoned that compounds incorporating both the 1,3,5-triazine and imino-coumarin pharmacophoric groups could be used in very effective antitumor agents as the hybridization of these two different bioactive molecules, which may lead to a synergistic effect. In this present study, we describe new hybrid compounds synthesized by linking 2,4-diamino-1,3,5-triazinyl moiety with coumarin or 2-imino-coumarin ring system (Figure 1).

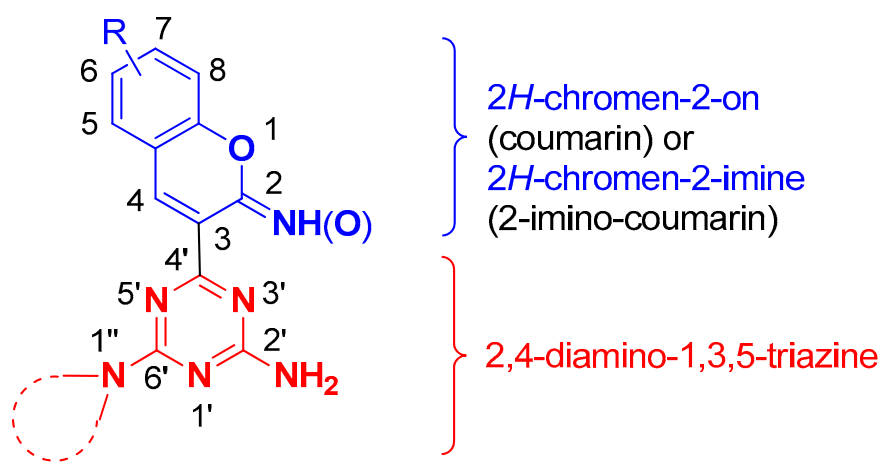

hybrid molecules

Figure 1. General structure of the hybrid molecules composed of 2,4-diamino-1,3,5-triazines and 2-imino-coumarins or coumarins.

\section{Results and Discussion}

\subsection{Synthesis of 2-Imino-2H-chromen-3-yl-1,3,5-triazine Derivatives (Imino-Coumarin Derivatives)}

2,4-Diaminotriazine derivatives 1-4 were prepared by cyclocondensation reaction of biguanides [66-68] with ethyl cyanoacetate according to the previously described methods $[64,66]$ (Scheme 1). 

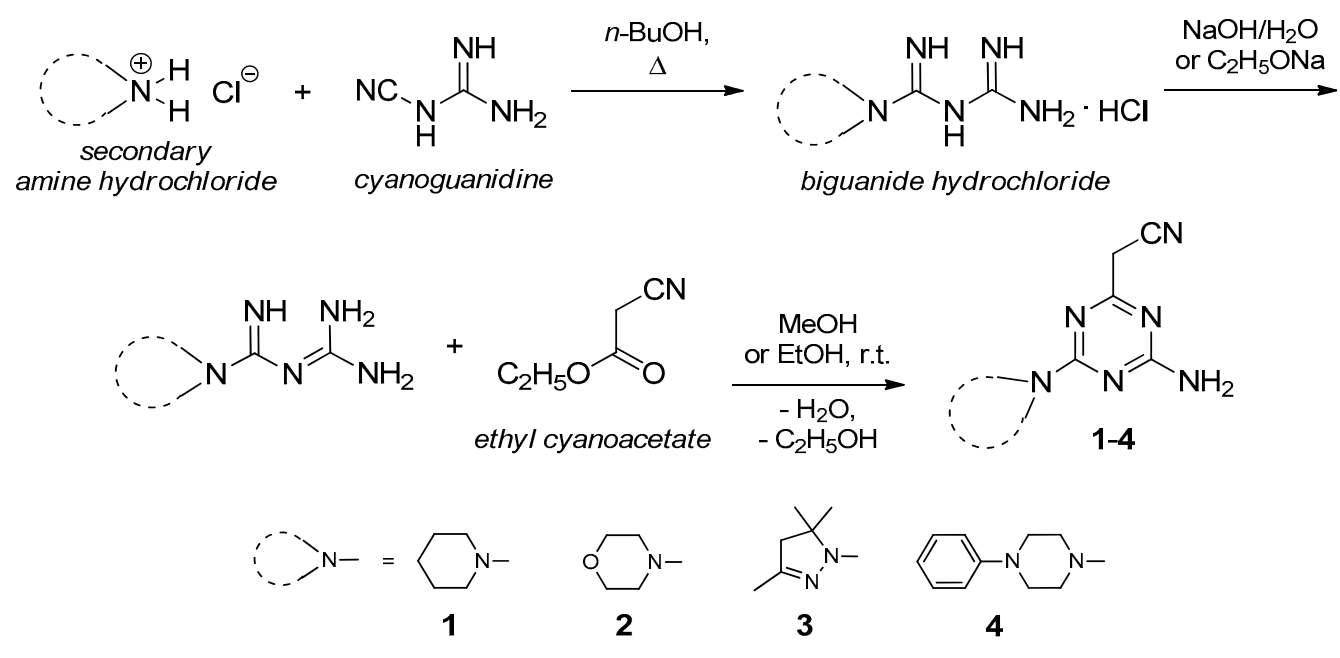

Scheme 1. Synthesis of 2-(4,6-diamine-1,3,5-triazin-2-yl)acetonitrile derivatives 1-4.

After this, the compounds bearing an active methylene group underwent a reaction with 2-hydroxybenzaldehydes in the presence of piperidine to give the desired hybrid 2-imino-2H-chromen-3-yl-1,3,5-triazine compounds 5-12 (Scheme 2). The reactions were carried out in $98 \%$ ethanol at $20-40{ }^{\circ} \mathrm{C}$ in the presence of piperidine as a basic catalyst. The best yields (49-61\%) were achieved by using 2-hydroxybenzaldehyde with electron-donating substituent, which was mainly 4-(diethylamino)-2-hydroxybenzaldehyde.

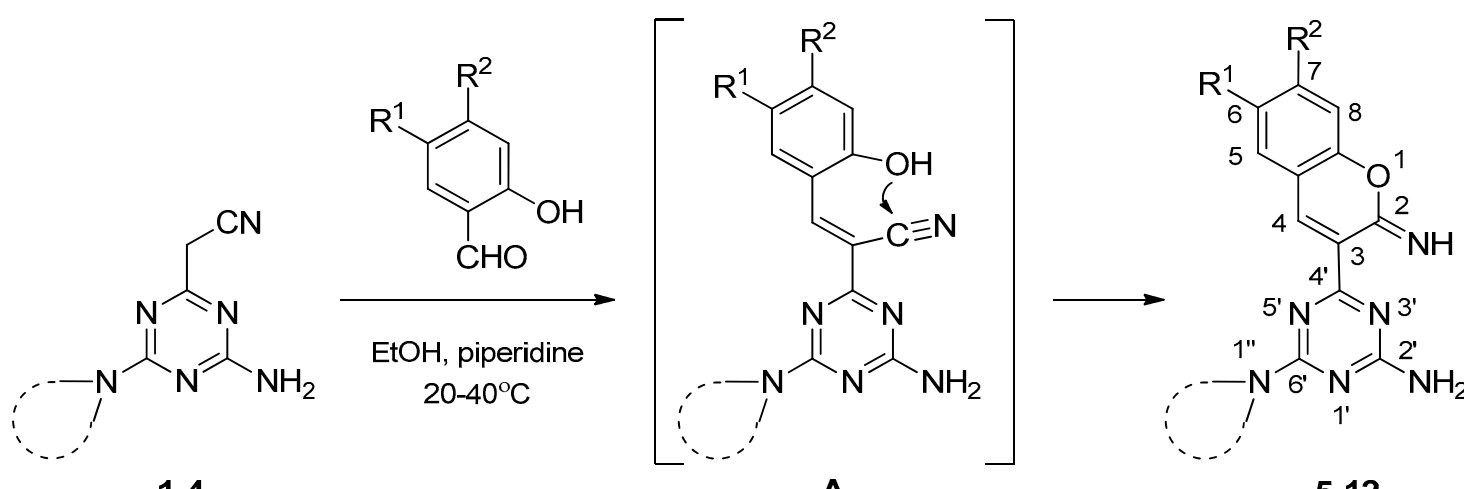

1-4

5-12

Comp.

Scheme 2. Synthesis of 2-imino-2H-chromen-3-yl-1,3,5-triazine derivatives 5-12. 
The structures of the 2-imino-coumarin derivatives 5-12 were confirmed by elemental analysis, IR and NMR spectra. In the IR spectra, N-H stretching vibrations of the $\mathrm{C}=\mathrm{N}-\mathrm{H}$ group and the primary amine group $\left(\mathrm{NH}_{2}\right)$ of the 1,3,5-triazine ring are observed in a range of 3500 to $3200 \mathrm{~cm}^{-1}$. In turn, ${ }^{1} \mathrm{H}-\mathrm{NMR}$ spectra contain a characteristic singlet representing the proton $\mathrm{C} 4-\mathrm{H}$ of the coumarin ring in a range of 7.43-8.57 ppm, while the proton signal of the imino group $\mathrm{C}=\mathrm{N} \underline{\mathrm{H}}$ appears in the region of 10.45-11.00 ppm.

However, during spectroscopic characterization of the compounds 7 and 9 containing pyrazoline moiety, we noted the presence of two rotamers with doubled signals found for the protons of the $\mathrm{C}=\mathrm{NH}$ group in the ${ }^{1} \mathrm{H}-\mathrm{NMR}$ spectra, which were recorded in DMSO- $d_{6}$ solution at $20-22{ }^{\circ} \mathrm{C}(293.15-295.15 \mathrm{~K})$. The ratio of the rotamers, which was deduced from the integration of the $\mathrm{C}=\mathrm{NH}$ proton signals, was $1: 1$ (see experimental section).

To obtain a better insight into the origin of signal doubling and the structures of the possible rotamers, we performed quantum chemical calculations for hybrid compound 7 [69]. The four possible rotamers $\mathbf{A}, \mathbf{B}, \mathbf{C}$ and $\mathbf{D}$ generated from the rotation around the bond axis $\mathrm{C} 3-\mathrm{C} 44^{\prime}$ (rotation of 2-imino-coumarin) and $\mathrm{C}^{\prime}-\mathrm{N} 1^{\prime \prime}$ (rotation pf pyrrazoline) are shown in Figure 2.

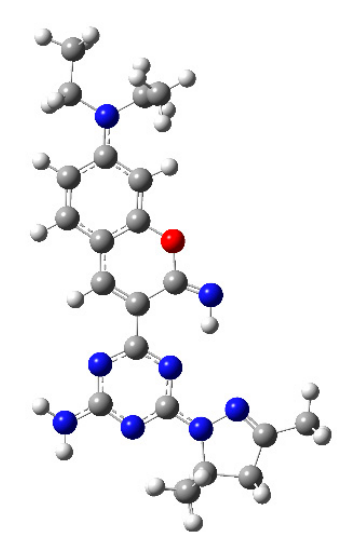

$7 \mathbf{A}$

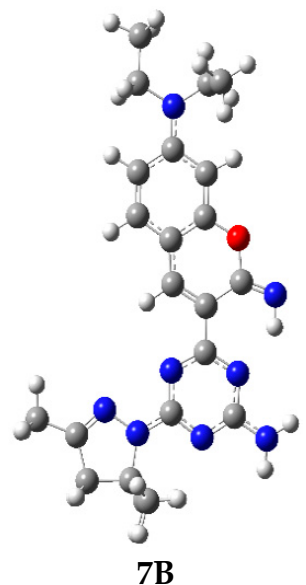

$-1368.47231 \quad-1368.471997$

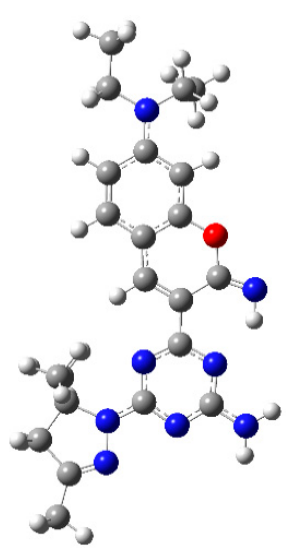

7C

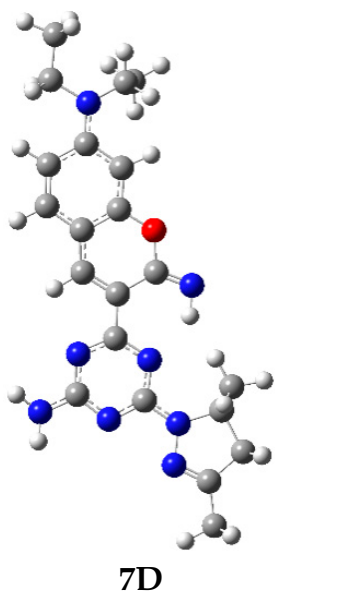

7D

E(DMSO) [a.u.]

$-1368.473135$

$-1368.470705$

$\Delta \mathrm{E}[\mathrm{kcal} / \mathrm{mol}]$

0

0.52

0.71

1.52

E(H2O) [a.u.]

$-1368.473524$

$-1368.472692$

$-1368.472381$

$-1368.471077$

$\Delta \mathrm{E}[\mathrm{kcal} / \mathrm{mol}]$

0

0.52

0.71

1.53

Figure 2. Structures of optimized rotamers 7A-D and corresponding electronic energies (E) and relative energies $(\triangle \mathrm{E})$ calculated at B3LYP /6-31(d) level of theory [70] using polarizable continuum model (PCM) solvation model [71].

The structure 7A was proven to be the lowest energy rotameric form both in DMSO and aqueous solution, while the energy differences between 7A and rotamers 7B, 7C and 7D were very low $(0.52-1.53$ $\mathrm{kcal} / \mathrm{mol}$ ). Therefore, we determined the barriers of $\mathrm{C} 3-\mathrm{C} 4^{\prime}$ and $\mathrm{C} 6^{\prime}-\mathrm{N} 1^{\prime \prime}$ bond rotations (Figure 3) and found that the barrier of $\mathrm{C}^{\prime}-\mathrm{N} 1^{\prime \prime}$ rotation was much higher $(15.2 \mathrm{kcal} / \mathrm{mol})$ than those of $\mathrm{C} 3-\mathrm{C} 4^{\prime}$ rotation $(8.5 \mathrm{kcal} / \mathrm{mol})$. It is significantly easier to overcome the later barrier under normal conditions (14-20 kcal/mol), which suggests that the two separate pairs of rotamers (7A, 7B) and (7C, 7D) may exist in the solution at room temperature, leading to a doubling of the $\mathrm{C} 2=\mathrm{NH}$ proton signal. 


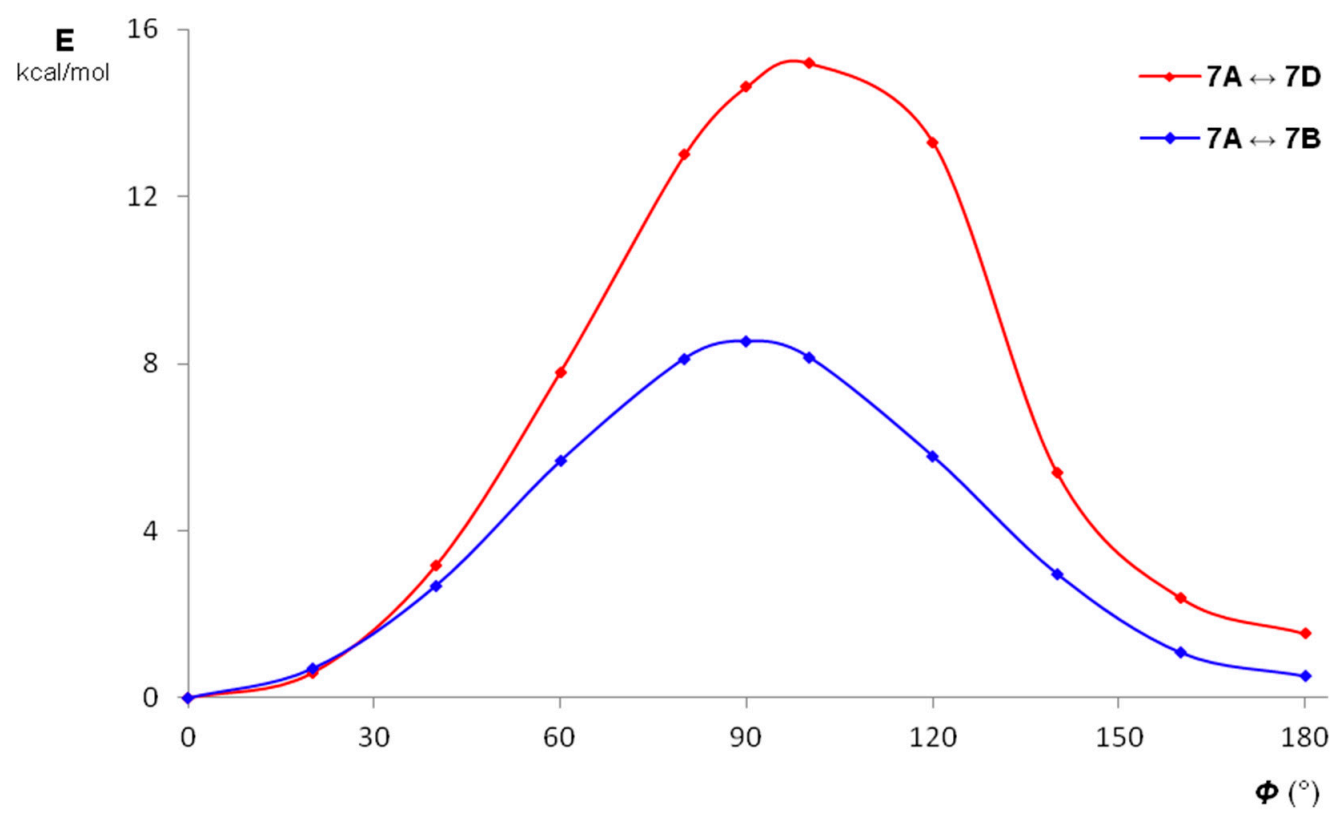

Figure 3. Profiles of the total energy difference with respect to the $180^{\circ}$ rotation of single bonds $\mathrm{C} 3-\mathrm{C} 4^{\prime}$ $(\mathbf{7 A} \leftrightarrow \mathbf{7 B})$ and $\mathrm{C}^{\prime}-\mathrm{N} 1^{\prime \prime}(\mathbf{7 A} \leftrightarrow 7 \mathrm{D})$.

\subsection{Synthesis of 2H-Chromen-3-yl-1,3,5-triazine Derivatives (Coumarin Derivatives)}

In a series of experiments aimed at the purification of 2-imino- $2 \mathrm{H}$-chromen-3-yl-1,3,5-triazines 10 and 12 by means of crystallization, we observed that using dimethylformamide containing $10 \%$ of water results in the hydrolysis of the imino group, which results in the formation of coumarin derivatives 13 and 14 (Scheme 3). Thus, the imino-coumarins were proven to be rather unstable under aqueous conditions and the presence of a mineral acid is not required for the hydrolysis of imino-coumarin derivatives as described previously [72].

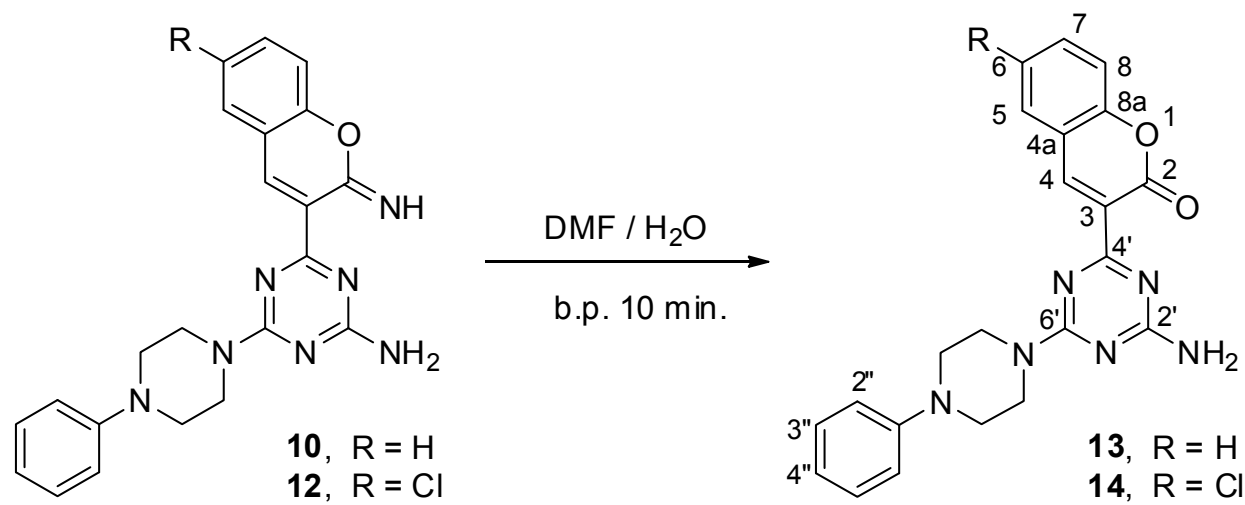

Scheme 3. Synthesis of 2H-chromen-3-yl-1,3,5-triazine derivatives 13 and 14.

The structures of the newly prepared compounds 13 and 14 were confirmed by elemental analyses and spectroscopic data (IR and NMR). Thus, in the IR spectra, strong absorptions that are attributable to the carbonyl group $(\mathrm{C}=\mathrm{O})$ at $1735 \mathrm{~cm}^{-1}$ are observed. In turn, the most diagnostic feature of the ${ }^{1} \mathrm{H}-\mathrm{NMR}$ spectra is the absence of signals corresponding to the protons of the $\mathrm{C} 2=\mathrm{N} \underline{\mathrm{H}}$ imino group. The characteristic $\mathrm{C} 4-\underline{\mathrm{H}}$ proton signals of coumarin ring are found at $8.55 \mathrm{ppm}$ (compound 13) and $8.54 \mathrm{ppm}$ (compound 14).

The ${ }^{13} \mathrm{C}-\mathrm{NMR}$ spectrum recorded for $2 \mathrm{H}$-chromen-3-yl-1,3,5-triazine derivative 13 (Scheme 3) revealed three signals of $C 2^{\prime}=\mathrm{N}, \mathrm{C} 4^{\prime}=\mathrm{N}$ and $\mathrm{C} 6^{\prime}=\mathrm{N}$ at $168.95,167.12$ and $164.73 \mathrm{ppm}$, which confirmed 
the presence of triazine moiety. The signals of the carbonyl group $(\mathrm{C} 2=\mathrm{O}), \mathrm{C} 8 \mathrm{a}$ (quaternary carbon atom) and C4-H of coumarin ring are located at 157.50, 154.13 and $144.41 \mathrm{ppm}$, respectively. The spectrum of 13 shows a signal at $151.25 \mathrm{ppm}$, which may be assigned to the quaternary carbon atom of phenylpiperazine. Carbon atoms of phenyl rings $\left(\mathrm{C}^{\prime \prime}-\mathrm{H}, \mathrm{C} 3^{\prime \prime}-\mathrm{H}, \mathrm{C} 4^{\prime \prime}-\mathrm{H}\right.$ of phenylpiperazine and $\mathrm{C} 3, \mathrm{C} 4 \mathrm{a}, \mathrm{C} 5-\mathrm{H}, \mathrm{C} 6-\mathrm{H}, \mathrm{C} 7-\mathrm{H}, \mathrm{C} 8-\mathrm{H}$ of coumarin) give signals in the range of 133.25-116.21 ppm. The aliphatic carbons of piperazine moiety are observed at the highest field (48.62 and $42.78 \mathrm{ppm})$.

2.3. In Vitro Cytotoxic Activity of 2-Imino-2H-chromen-3-yl-1,3,5-triazines (Imino-Coumarins 5-12) and 2H-Chromen-3-yl-1,3,5-triazines (Coumarins 13, 14)

The in vitro cytotoxic properties of compounds were evaluated by the crystal violet microtiter plate assay as described earlier [73] with a panel of five human tumor cell lines: human pancreatic cancer cell line DAN-G, human lung cancer line A-427, human non-small cell lung cancer cell line LCLC-103H, human cervix cancer cell line SISO and human urinary bladder cancer cell line RT-4. This assay measures the antiproliferative potencies of compounds towards actively dividing cancer cells. Primary screening was performed to indicate whether a compound possesses enough activity at a concentration of $20 \mu \mathrm{M}$ to inhibit cell growth by $50 \%$. The secondary screening was aimed at the determination of cytotoxic potencies. The $\mathrm{IC}_{50}$ values were obtained after $96-\mathrm{h}$ exposure to the 2-imino-coumarin derivatives 5-12 and the coumarin derivatives $\mathbf{1 3}$ and $\mathbf{1 4}$. The $\mathrm{IC}_{50}$ values calculated from the dose-response data are presented in Table 1 and Figure 4.

The compounds tested can be divided into two series: (1) derivatives 5-9 containing a small heterocyclic moiety at the position $6^{\prime}$ of the triazine ring and (2) analogues 10-12 substituted with a bulky lipophilic 4-phenylpiperazine moiety. In the first series, the most potent substances were compounds 6 and 7 with the basic electron-donating diethylamino substituent at the position 7 of 2-iminocoumarin ring $\left(\mathrm{IC}_{50}\right.$ in the range of 5.67-9.21 $\mu \mathrm{M}$ and 8.16-15.02 $\mu \mathrm{M}$, respectively). On the other hand, the lowest activity showed the analogue 8 bearing electron-withdrawing Br substituent at the position 6 ( $\mathrm{IC}_{50}$ in the range of $\left.7.69-28.25 \mu \mathrm{M}\right)$.

The same pattern was seen in the second series of 4-phenylpiperazine-containing compounds. The substitution of $\mathbf{1 0}$ with a basic electron-withdrawing $\mathrm{Cl}$ substituent, which creates $\mathbf{1 2}$, considerably reduced the cytotoxic activity $\left(\mathrm{IC}_{50}\right.$ in the range of $8.35-21.12 \mu \mathrm{M}$ vs. $26.32-37.19 \mu \mathrm{M}$ ), while the introduction of a basic electron-donating diethylamino group at the position 7 resulted in the most potent compound 11, which showed slightly lower cytotoxic activities than cisplatin $\left(\mathrm{IC}_{50}\right.$ values $1.51-2.60 \mu \mathrm{M}$ vs. $0.06-0.15 \mathrm{mM}$ ).

It should be noted that the transformation of 2-iminocoumarins $\mathbf{1 0}$ and $\mathbf{1 2}$ into the corresponding coumarins $\mathbf{1 3}$ and $\mathbf{1 4}$ did not improve their cytotoxic properties (see Table 1 and Figure 4). 
Table 1. Cytotoxic activity of 2-imino-2H-chromen-3-yl-1,3,5-triazines 5-12 and 2H-chromen3-yl-1,3,5-triazines $\mathbf{1 3}, \mathbf{1 4}$ on five human tumor cell lines ( $\left.\mathrm{IC}_{50} \pm \mathrm{SD}, \mu \mathrm{M}\right)$ compared to cisplatin (CDDP).

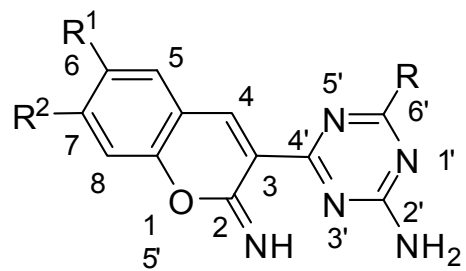

\begin{tabular}{|c|c|c|c|c|c|c|c|c|c|}
\hline No. & $\mathbf{R}$ & $\mathbf{R}^{1}$ & $\mathbf{R}^{2}$ & $\mathrm{X}$ & DAN-G & A-427 & LCLC & SISO & RT-4 \\
\hline 5 & & $\mathrm{H}$ & $\mathrm{H}$ & $\mathrm{NH}$ & $\begin{array}{c}15.12 \pm \\
5.79\end{array}$ & $\begin{array}{c}9.04 \pm \\
4.55\end{array}$ & $\begin{array}{c}14.17 \pm \\
12.98\end{array}$ & $\begin{array}{c}21.33 \pm \\
2.69\end{array}$ & $\begin{array}{c}16.24 \pm \\
6.15\end{array}$ \\
\hline 6 & & $\mathrm{H}$ & $\left(\mathrm{C}_{2} \mathrm{H}_{5}\right)_{2} \mathrm{~N}$ & $\mathrm{NH}$ & $\begin{array}{c}9.21 \pm \\
0.59\end{array}$ & $\begin{array}{c}7.62 \pm \\
0.27\end{array}$ & $\begin{array}{c}6.18 \pm \\
1.26\end{array}$ & $\begin{array}{c}5.67 \pm \\
0.80\end{array}$ & $\begin{array}{c}8.37 \pm \\
1.66\end{array}$ \\
\hline 7 & & $\mathrm{H}$ & $\left(\mathrm{C}_{2} \mathrm{H}_{5}\right)_{2} \mathrm{~N}$ & $\mathrm{NH}$ & $\begin{array}{c}11.19 \pm \\
0.55\end{array}$ & $\begin{array}{c}8.16 \pm \\
3.08\end{array}$ & $\begin{array}{c}15.02 \pm \\
0.82\end{array}$ & $\begin{array}{c}11.64 \pm \\
1.69\end{array}$ & $\begin{array}{c}11.04 \pm \\
6.49\end{array}$ \\
\hline 8 & & $\mathrm{Br}$ & $\mathrm{H}$ & $\mathrm{NH}$ & $\begin{array}{c}28.25 \pm \\
4.06\end{array}$ & $\begin{array}{c}26.87 \pm \\
2.45\end{array}$ & $\begin{array}{c}27.42 \pm \\
4.00\end{array}$ & $\begin{array}{c}7.69 \pm \\
1.72\end{array}$ & $\begin{array}{c}21.40 \pm \\
2.39\end{array}$ \\
\hline 9 & & $\mathrm{CH}_{3}$ & $\mathrm{H}$ & $\mathrm{NH}$ & $\begin{array}{c}11.91 \pm \\
0.52\end{array}$ & $\begin{array}{c}13.56 \pm \\
1.45\end{array}$ & $\begin{array}{c}15.47 \pm \\
1.84\end{array}$ & $\begin{array}{c}14.44 \pm \\
2.49\end{array}$ & $\begin{array}{c}6.91 \pm \\
0.62\end{array}$ \\
\hline 10 & & $\mathrm{H}$ & $\mathrm{H}$ & $\mathrm{NH}$ & $\begin{array}{c}8.35 \pm \\
0.87\end{array}$ & $\begin{array}{c}14.79 \pm \\
0.45\end{array}$ & $\begin{array}{c}21.12 \pm \\
2.69\end{array}$ & $\begin{array}{c}15.24 \pm \\
0.73\end{array}$ & $\begin{array}{c}16.24 \pm \\
6.15\end{array}$ \\
\hline 11 & & $\mathrm{H}$ & $\left(\mathrm{C}_{2} \mathrm{H}_{5}\right)_{2} \mathrm{~N}$ & $\mathrm{NH}$ & $\begin{array}{c}2.14 \pm \\
0.25\end{array}$ & $\begin{array}{c}1.51 \pm \\
0.17\end{array}$ & $\begin{array}{c}2.21 \pm \\
0.39\end{array}$ & $\begin{array}{c}2.60 \pm \\
0.37\end{array}$ & $\begin{array}{c}1.66 \pm \\
0.25\end{array}$ \\
\hline 12 & & $\mathrm{Cl}$ & $\mathrm{H}$ & $\mathrm{NH}$ & $\begin{array}{c}23.26 \pm \\
6.62\end{array}$ & $\begin{array}{c}37.19 \pm \\
6.09\end{array}$ & $\begin{array}{c}34.24 \pm \\
3.05\end{array}$ & $\begin{array}{c}29.86 \pm \\
6.13\end{array}$ & $\begin{array}{c}26.32 \pm \\
2.99\end{array}$ \\
\hline 13 & & $\mathrm{H}$ & $\mathrm{H}$ & $\mathrm{O}$ & $\begin{array}{c}31.44 \pm \\
5.98\end{array}$ & $>50$ & $\begin{array}{c}19.82 \pm \\
1.12\end{array}$ & $\begin{array}{c}32.73 \pm \\
2.33\end{array}$ & $\begin{array}{c}37.73 \pm \\
3.13\end{array}$ \\
\hline 14 & & $\mathrm{Cl}$ & $\mathrm{H}$ & $\mathrm{O}$ & $\begin{array}{c}15.87 \pm \\
1.73\end{array}$ & $\begin{array}{c}25.95 \pm \\
10.95\end{array}$ & $\begin{array}{c}17.15 \pm \\
1.56\end{array}$ & $\begin{array}{c}29.15 \pm \\
7.64\end{array}$ & $\begin{array}{c}36.14 \pm \\
7.00\end{array}$ \\
\hline \multicolumn{5}{|c|}{ cisplatin (CDDP) reference [73] } & $\begin{array}{c}0.73 \pm \\
0.34\end{array}$ & $\begin{array}{c}1.96 \pm \\
0.54\end{array}$ & $\begin{array}{c}0.90 \pm \\
0.19\end{array}$ & $\begin{array}{c}0.24 \pm \\
0.06\end{array}$ & $\begin{array}{c}1.61 \pm \\
0.16\end{array}$ \\
\hline
\end{tabular}




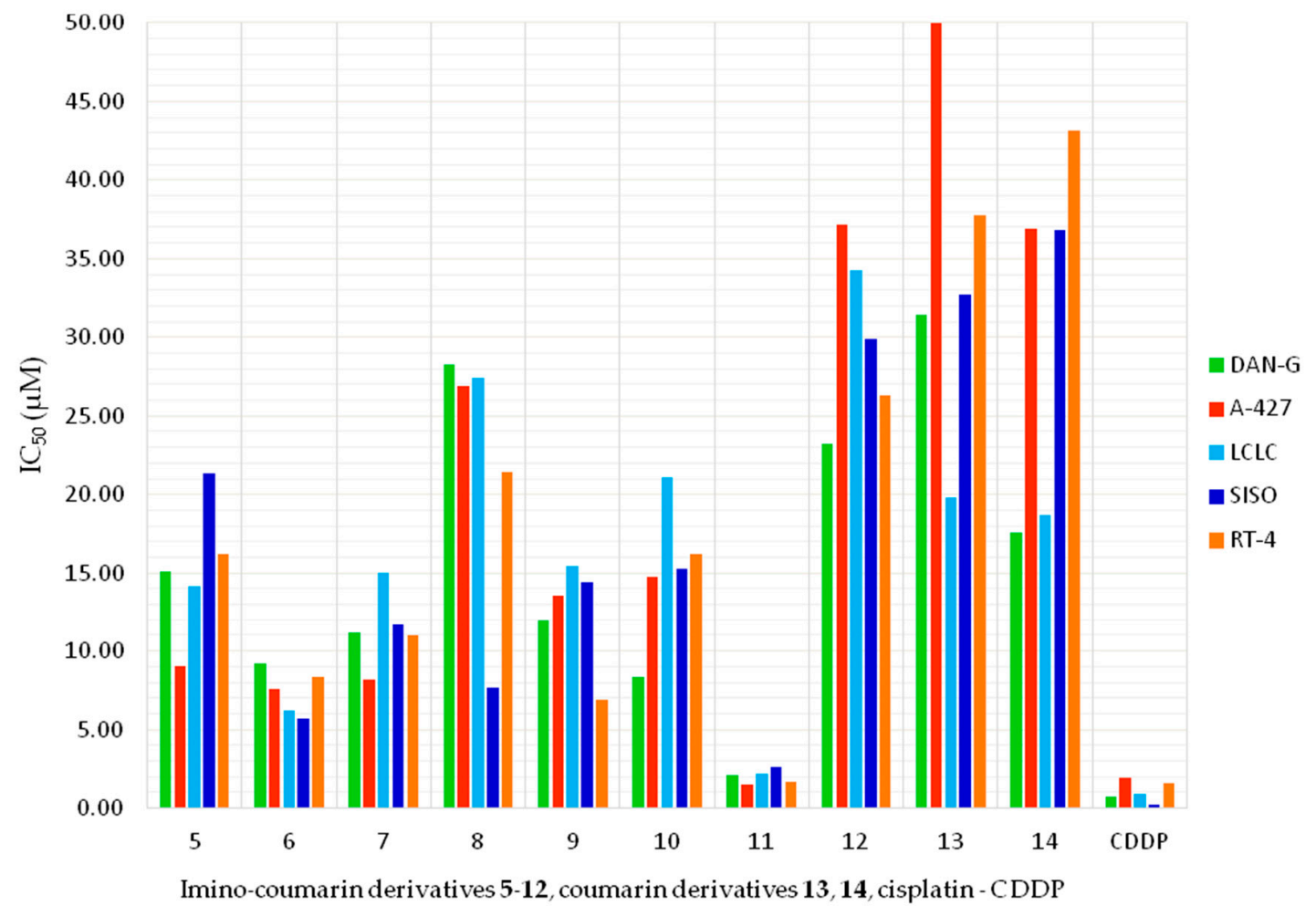

Figure 4. $\mathrm{IC}_{50}(\mu \mathrm{M})$ values of 2-imino-2H-chromen-3-yl-1,3,5-triazines $\mathbf{5 - 1 2}$ and 2H-chromen-3-yl-1,3,5-triazines 13, 14 on five human tumor cell lines (DAN-G, A-427, LCLC, SISO, RT-4) compared to cisplatin (CDDP).

\section{Experimental Section}

The melting points were determined with a Boëtius apparatus and are uncorrected. The infrared spectra were obtained on KBr pastilles using a Nicolet 380 FT-IR (Thermo Fisher Scientific, Waltham, MA, USA). Magnetic resonance spectra (NMR) were recorded with a Varian Gemini $200 \mathrm{BB}(200 \mathrm{MHz})$ spectrometer (Varian Inc. Palo Alto, CA, USA) and Varian Unity Inova 500 (500 MHz) spectrometer in $200 \mathrm{MHZ}$ in a DMSO- $d_{6}$ solution. The residual peak of the solvent was used as an internal standard. Chemical shifts $(\delta)$ are given in ppm. Coupling constants $(J)$ are given in $\mathrm{Hz}$. The elemental analyses of carbon, hydrogen and nitrogen determined for compounds were within $\pm 0.4 \%$ of the theoretical values.

All cell culture reagents were purchased from Sigma (Deisenhofen, FRG). The cancer cell lines used included the following: human large cell lung carcinoma (LCLC-103H), human urinary bladder carcinoma (5637), human lung carcinoma (A-427), human uterine cervical adenocarcinoma (SISO), human bladder cell carcinoma (RT-4) and human pancreas cell adenocarcinoma (DAN-G). These cancer cell lines were obtained from the German Collection of Microorganisms and Cell Cultures (DSMZ, Braunschweig, FRG). The culture medium for cell lines was a RPMI-1640 medium containing $2 \mathrm{~g} / \mathrm{L}$ $\mathrm{HCO}_{3}$ and $10 \%$ FCS. Cells were incubated in a humid atmosphere of $5 \% \mathrm{CO}_{2}$ at $37{ }^{\circ} \mathrm{C}$ in $75 \mathrm{~cm}^{2}$ plastic culture flasks (Sarstedt, Nümbrecht, FRG) and were passaged shortly before becoming confluent. For the cytotoxicity studies, $100 \mu \mathrm{L}$ of a cell suspension was seeded into 96-well microtiter plates (Sarstedt) at a density of 1000 cell per well except for the LCLC-103H cell line, which was plated out at 250 cells per well. One day after plating, the cells were treated with the test substance at five concentrations per compound. The 1000-fold concentrated stock solutions in DMF or DMSO were serially diluted by $50 \%$ in DMF or DMSO to give the feed solutions, which were diluted by 500 -fold in the culture medium. The controls received DMF or DMSO. Each concentration was tested in eight wells, with each well receiving $100 \mu \mathrm{L}$ of the medium containing the substance. The concentration ranges were chosen to bracket the expected $\mathrm{IC}_{50}$ values as best as possible. The cells were incubated for 
$96 \mathrm{~h}$. After this, the medium was removed and replaced with $1 \%$ glutaraldehyde/PBS. Optical density (OD) was measured at $\lambda=570 \mathrm{~nm}$ by use of a Sunrise plate reader (Anthos 2010, Salzburg, Austria). Corrected $\mathrm{T} / \mathrm{C}$ values were calculated according to the following equation:

$$
(T / C)_{\text {corr }(\%)}=(\text { O.D.T }- \text { O.D.c.0 }) /(\text { O.D.C }- \text { O.D.c.0 }) \times 100
$$

where O.D.T is the mean absorbance of the treated cells; O.D.C is the mean absorbance of the controls; and O.D.c.0 is the mean absorbance at the time that the drug was added. The $\mathrm{IC}_{50}$ values were estimated by a linear least-square regression of the $T / C_{\text {corr }}$ values compared to the logarithm of the substance concentration. Only the concentrations that yielded $T / C_{\text {corr }}$ values between $10 \%$ and $90 \%$ were used in the calculation. The reported $\mathrm{IC}_{50}$ values are the averages of three independent experiments.

\subsection{General Procedure for Preparation of Biguanide Hydrochlorides (Scheme 1)}

Cyanoguanidine (dicyandiamide) $(2.86 \mathrm{~g}, 34 \mathrm{mmol})$ was added to an appropriate solution of amine hydrochloride $(34 \mathrm{mmol})$ in anhydrous $n$-butanol $(10 \mathrm{~mL})$. The mixture was carefully heated until the exothermic reaction was initiated $\left(\mathrm{ca} .90^{\circ} \mathrm{C}\right.$ ) before being stirred at $122-123^{\circ} \mathrm{C}$ for $8 \mathrm{~h}$. After cooling, the mixture was stirred for a further $6 \mathrm{~h}$ at room temperature. The next day, the precipitate was filtered, washed with $n$-butanol and isopropanol and purified by crystallization using methanol.

Another method described in reference [74] involves the fusion of an equimolar mixture of an amine hydrochloride and cyanoguanidine at $130-150{ }^{\circ} \mathrm{C}$ for $0.5-2 \mathrm{~h}$.

\subsection{Synthesis of 2-[4,6-Diamine-1,3,5-triazin-2-yl]acetonitrile Derivatives 1, $\mathbf{3}$ and $\mathbf{4}$}

Sodium metal $(0.584 \mathrm{~g}, 25.4 \mathrm{mmol})$ was added slowly with stirring to anhydrous ethanol (36 mL), before the mixture was stirred under gentle reflux. The appropriate amount of biguanide hydrochloride ( $25.4 \mathrm{mmol}$ ) was added to the obtained solution of sodium ethoxide in ethanol. The mixture was cooled and stirred at room temperature for $2 \mathrm{~h}$. The ethyl cyanoacetate $(25.4 \mathrm{mmol}, 2.03 \mathrm{~mL}$, $\mathrm{d}=1.418 \mathrm{~g} / \mathrm{mL})$ was added dropwise at room temperature $\left(20-22{ }^{\circ} \mathrm{C}\right)$ to a stirred solution over the next hour. The precipitate was filtered, washed with ethanol and crystallized from the appropriate solvent.

The compounds 1, 3 and 4 were obtained by the following procedure:

2-[4-Amino-6-(piperidin-1-yl)-1,3,5-triazin-2-yl]acetonitrile (1), Yield $2.6 \mathrm{~g} \mathrm{(47 \% );} \mathrm{m.p.} 126-127^{\circ} \mathrm{C}(\mathrm{MeOH})$; IR (KBr) $v_{\max }\left(\mathrm{cm}^{-1}\right): 3462,3355,3245,3006,2961,2927,2860,2257,1651,1578,1550,1515,1465,1446$, $1389,1369,1290,994,805 ;{ }^{1} \mathrm{H}-\mathrm{NMR}\left(200 \mathrm{MHz}, \mathrm{DMSO}-d_{6}\right) \delta(\mathrm{ppm}): 1.40-1.70\left(\mathrm{~m}, 6 \mathrm{H}, 3 \times \mathrm{CH}_{2}\right), 3.60-3.80$ $\left(\mathrm{m}, 4 \mathrm{H}, 2 \times \mathrm{CH}_{2}\right), 3.85$ (s, $\left.2 \mathrm{H}, \mathrm{CH}_{2}\right) ; 6.97$ (br.s, $2 \mathrm{H}, \mathrm{NH}_{2}$ ). Anal. calcd for $\mathrm{C}_{10} \mathrm{H}_{14} \mathrm{~N}_{6}(218.26)$ :, $55.03 ; \mathrm{H}$, 6.47; N, 38.50. Found: C, 54.98; H, 6.38; N, 38.46.

2-[4-Amino-6-(3,5,5-trimethyl-4,5-dihydro-1H-pyrazol-1-yl)-1,3,5-triazin-2-yl]acetonitrile (3), Yield $3.00 \mathrm{~g}$ (48\%); m.p. $244-245^{\circ} \mathrm{C}(n-\mathrm{BuOH})$, reference [64]: 246-247 ${ }^{\circ} \mathrm{C}$; IR (KBr) $v_{\max }\left(\mathrm{cm}^{-1}\right): 3354,3214,2951$, $2924,2261,1655,1539,1469,1447,1380,1335,1149,969,932,807,608 .{ }^{1} \mathrm{H}-\mathrm{NMR}\left(200 \mathrm{MHz}, \mathrm{DMSO}-d_{6}\right) \delta$ (ppm): 1.57 (s, 6H, 2xCH $), 1.99\left(\mathrm{~s}, 3 \mathrm{H}, \mathrm{CH}_{3}\right), 2.83\left(\mathrm{~s}, 2 \mathrm{H}, \mathrm{CH}_{2}\right), 3.92\left(\mathrm{~s}, 2 \mathrm{H}, \mathrm{CH}_{2}\right) ; 7.10(\mathrm{~s}, 1 \mathrm{H}, \mathrm{NH}), 7.40$ (s, $1 \mathrm{H}, \mathrm{NH}$ ). Anal. calcd for $\mathrm{C}_{11} \mathrm{H}_{15} \mathrm{~N}_{7}$ (245.28): C, 53.86; H, 6.16; N, 39.97. Found: C, 53.78; H, 6.18; $\mathrm{N}, 39.86$.

2-[4-Amino-6-(4-phenylpiperazin-1-yl)-1,3,5-triazin-2-yl]acetonitrile (4), Yield $4.5 \mathrm{~g}(60 \%) ;$ m.p. $207-209{ }^{\circ} \mathrm{C}$ (DMF-H $\left.{ }_{2} \mathrm{O}\right)$, reference [66]: 205-208 ${ }^{\circ} \mathrm{C}$; IR (KBr) $v_{\max }\left(\mathrm{cm}^{-1}\right): 3433,3322,3149,2963,2908,2814,2259$, 1656, 1553, 1494, 1476, 1443, 1386, 1370, 1332, 1282, 1240, 1146, 1004, 919, 801, 761, 696; ${ }^{1} \mathrm{H}-\mathrm{NMR}$ (500 MHz, DMSO-d 6 ) $\delta(\mathrm{ppm}): 3.14-3.28\left(\mathrm{~m}, 4 \mathrm{H}, 2 \mathrm{xCH}_{2}\right), 3.82-3.90\left(\mathrm{~m}, 4 \mathrm{H}, 2 \mathrm{CH}_{2}\right), 3.91\left(\mathrm{~s}, 2 \mathrm{H}, \mathrm{CH}_{2}\right)$, $6.82(\mathrm{t}, 1 \mathrm{H}, \mathrm{CH}), 6.99(\mathrm{~d}, J=7.8 \mathrm{~Hz}, 2 \mathrm{H}, 2 \mathrm{xCH}), 7.06(\mathrm{~s}, 1 \mathrm{H}, \mathrm{NH}), 7.15(\mathrm{~s}, 1 \mathrm{H}, \mathrm{NH}), 7.24(\mathrm{t}, 2 \mathrm{H}, 2 \mathrm{CH})$. Anal. calcd for $\mathrm{C}_{15} \mathrm{H}_{17} \mathrm{~N}_{7}$ (295.34): C, 61.00; H, 5.80; N, 33.20. Found: C, 60.92; H, 5.74; N, 33.12. 


\subsection{Synthesis of 2-(4-amino-6-morpholino-1,3,5-triazin-2-yl)acetonitrile (2)}

Ethyl cyanoacetate $(3.46 \mathrm{~g}, 3.44 \mathrm{~mL}, 30.57 \mathrm{mmol}, \mathrm{d}=1.418 \mathrm{~g} / \mathrm{mL})$ was added dropwise to a solution of $\mathrm{N}$-carbamimidoylmorpholine-4-carboximidamide $(5.23 \mathrm{~g}, 30.57 \mathrm{mmol})$ in anhydrous methanol $(48 \mathrm{~mL})$ over $1 \mathrm{~h}$. The mixture was stirred for $2 \mathrm{~h}$ at room temperature $\left(20-22^{\circ} \mathrm{C}\right)$. The precipitate was filtered and washed with cold methanol $\left(5^{\circ} \mathrm{C}\right)$. The product was crystallized from methanol. Yield $3.2 \mathrm{~g}(48 \%)$; m.p. $164-165^{\circ} \mathrm{C}(\mathrm{MeOH})$, reference [66]: $178-180{ }^{\circ} \mathrm{C}$; IR $(\mathrm{KBr}) v_{\max }\left(\mathrm{cm}^{-1}\right)$ : 3352, 3315, $3202,2974,2951,2258,1650,1574,1530,1471,1447,1380,1335,1152,969,808,631 ;{ }^{1} \mathrm{H}-\mathrm{NMR}(200 \mathrm{MHz}$, DMSO- $\left.d_{6}\right) \delta(\mathrm{ppm}): 3.55-3.63\left(\mathrm{~m}, 4 \mathrm{H}, 2 \mathrm{CCH}_{2}\right), 3.64-3.75\left(\mathrm{~m}, 4 \mathrm{H}, 2 \mathrm{CCH}_{2}\right) ; 3.88\left(\mathrm{~s}, 2 \mathrm{H}, \mathrm{CH}_{2}\right), 7.04(\mathrm{~s}, 1 \mathrm{H}$, $\mathrm{NH}), 7.12(\mathrm{~s}, 1 \mathrm{H}, \mathrm{NH})$. Anal. calcd. for $\mathrm{C}_{9} \mathrm{H}_{12} \mathrm{~N}_{6} \mathrm{O}$ (220.23): C, 49.08; $\mathrm{H}, 5.49 ; \mathrm{N}, 38.16$. Found: $\mathrm{C}, 49.02$; $\mathrm{H}, 5.41 ; \mathrm{N}, 38.18$.

\subsection{Synthesis of 2-Imino-2H-chromen-3-yl-1,3,5-triazine Derivatives 5-12 (General Procedure)}

An appropriate amount of 2-hydroxybenzaldehyde derivative $(13 \mathrm{mmol})$ was added gradually to a suspension of an appropriate amount of 1,3,5-triazineacetonitrile 1-4 (10 mmol) in $98 \%$ ethanol $(30 \mathrm{~mL})$. After $3 \mathrm{~min}$ of stirring, piperidine $(0.2 \mathrm{~mL})$ was added dropwise to the solution. The mixture was heated for $30 \mathrm{~min}$ at $40{ }^{\circ} \mathrm{C}$ and cooled. Stirring was continued at room temperature $\left(20-22{ }^{\circ} \mathrm{C}\right)$ for $18 \mathrm{~h}$. The precipitate was filtered, washed with anhydrous ethanol $(3 \times 2 \mathrm{~mL})$ and dried. The imino-coumarin derivatives 5-12 were proven to be unstable upon heating in protic solvents. They also decomposed when we attempted chromatographic purification on silica gel. Therefore, the products washed with cold ethanol were used for structural and biological investigations.

The following compounds were obtained by the following procedure:

4-(2-Imino-2H-chromen-3-yl)-6-(piperidin-1-yl)-1,3,5-triazin-2-amine (5), Yellow powder $0.67 \mathrm{~g}(21 \%) ; \mathrm{m} . \mathrm{p}$. 216-217 ${ }^{\circ} \mathrm{C}$; IR (KBr) $v_{\max }\left(\mathrm{cm}^{-1}\right): 3339,3213,3047,2941,2850,1650,1613,1598,1541,1513,1456,1395$, 1294, 1237, 818, 760; ${ }^{1} \mathrm{H}-\mathrm{NMR}$ (200 MHz, DMSO- $\left.d_{6}\right) \delta(\mathrm{ppm}): 1.40-1.75\left(\mathrm{~m}, 6 \mathrm{H}, 3 \mathrm{xCH}_{2}\right), 3.65-3.85$ $\left(\mathrm{m}, 4 \mathrm{H}, 2 \mathrm{CCH}_{2}\right), 6.95-7.30\left(\mathrm{~m}, 4 \mathrm{H}, 2 \times \mathrm{CH}+\mathrm{NH}_{2}\right), 7.45-7.60(\mathrm{~m}, 1 \mathrm{H}, \mathrm{CH}), 7.67(\mathrm{~d}, J=7.3 \mathrm{~Hz}, 1 \mathrm{H}, \mathrm{CH})$, $8.50(\mathrm{~s}, 1 \mathrm{H}, \mathrm{CH}), 10.71(\mathrm{~s}, 1 \mathrm{H}, \mathrm{NH})$. Anal. calcd for $\mathrm{C}_{17} \mathrm{H}_{18} \mathrm{~N}_{6} \mathrm{O}$ (322.36): C, 63.34; $\mathrm{H}, 5.63 ; \mathrm{N}, 26.07$. Found: C, 63.28; H, 5.51; N, 25.98 .

4-[7-(Diethylamino)-2-imino-2H-chromen-3-yl]-6-morpholino-1,3,5-triazin-2-amine (6), Yellow powder, yield $2.41 \mathrm{~g} \mathrm{(61 \% );} \mathrm{m.p.} 232-233{ }^{\circ} \mathrm{C}$; IR (KBr) $v_{\max }\left(\mathrm{cm}^{-1}\right)$ : 3443, 3333, 3210, 2967, 2924, 2854, 1654, 1603, 1508, 1440, 1398, 1351, 1280, 1236, 1137, 816; ${ }^{1} \mathrm{H}-\mathrm{NMR}\left(500 \mathrm{MHz}\right.$, DMSO-d $\left.{ }_{6}\right) \delta(\mathrm{ppm}): 1.14(\mathrm{t}, 6 \mathrm{H}$, $\left.2 \times \mathrm{CH}_{3}\right), 3.44\left(\mathrm{q}, 4 \mathrm{H}, 2 \times \mathrm{CH}_{2}\right), 3.60-3.69\left(\mathrm{~m}, 4 \mathrm{H}, 2 \mathrm{xCH}_{2}\right), 3.70-3.85\left(\mathrm{~m}, 4 \mathrm{H}, 2 \mathrm{xCH}_{2}\right), 6.39(\mathrm{~s}, 1 \mathrm{H}, \mathrm{CH}), 6.55$ $(\mathrm{d}, J=8.8 \mathrm{~Hz}, 1 \mathrm{H}, \mathrm{CH}), 7.00(\mathrm{~s}, 1 \mathrm{H}, \mathrm{NH}), 7.12(\mathrm{~s}, 1 \mathrm{H}, \mathrm{NH}), 7.39(\mathrm{~d}, J=8.8 \mathrm{~Hz}, 1 \mathrm{H}, \mathrm{CH}), 8.45(\mathrm{~s}, 1 \mathrm{H}, \mathrm{CH})$, 10.48 (s, $1 \mathrm{H}, \mathrm{NH}$ ). Anal. calcd for $\mathrm{C}_{20} \mathrm{H}_{25} \mathrm{~N}_{7} \mathrm{O}_{2}$ (395.46): $\mathrm{C}, 60.74 ; \mathrm{H}, 6.37 ; \mathrm{N}, 24.79$. Found: $\mathrm{C}, 60.68 ; \mathrm{H}$, $6.31 ; \mathrm{N}, 24.57$.

4-[7-(Diethylamino)-2-imino-2H-chromen-3-yl]-6-(3,5,5-trimethyl-4,5-dihydro-1H-pyrazol-1-yl)-1,3,5-triazin2-amine (7), Orange powder, yield $2.05 \mathrm{~g}(49 \%) ;$ m.p. 232-233 ${ }^{\circ} \mathrm{C}$; IR (KBr) $v_{\max }\left(\mathrm{cm}^{-1}\right)$ : 3464, 3289, 3175, 2974, 2930, 1652, 1603, 1439, 1383, 1352, 1332, 1248, 1143, 1075, 811; ${ }^{1}$ H-NMR (500 MHz, DMSO- $\left.d_{6}\right) \delta(\mathrm{ppm}): 1.11\left(\mathrm{t}, 6 \mathrm{H}, 2 \mathrm{xCH}_{3}\right), 1.61\left(\mathrm{~s}, 6 \mathrm{H}, 2 \mathrm{CCH}_{3}\right), 1.99\left(\mathrm{~s}, 3 \mathrm{H}, \mathrm{CH}_{3}\right), 2.84\left(\mathrm{~s}, 2 \mathrm{H}, \mathrm{CH}_{2}\right), 3.42$ $\left(\mathrm{q}, 4 \mathrm{H}, 2 \mathrm{CCH}_{2}\right), 6.37(\mathrm{~s}, 1 \mathrm{H}, \mathrm{CH}), 6.51\left(\mathrm{dd}, J_{1}=2.4 \mathrm{~Hz}, J_{2}=8.8 \mathrm{~Hz}, 1 \mathrm{H}, \mathrm{CH}\right), 7.00$ (br.s, $\left.2 \mathrm{H}, \mathrm{NH}_{2}\right), 7.33$ (d, J = 8.8 Hz, 1H, CH), 8.32 (s, $1 \mathrm{H}, \mathrm{CH}), 10.45$ (br.s, 0.5H, NH), 10.82 (br.s, 0.5H, NH). Anal. calcd for $\mathrm{C}_{22} \mathrm{H}_{28} \mathrm{~N}_{8} \mathrm{O}$ (420.51): C, 62.84; H, 6.71; N, 26.65. Found: C, 62.68; H, 6.64; N, 26.58.

4-(6-Bromo-2-imino-2H-chromen-3-yl)-6-(3,5,5-trimethyl-4,5-dihydro-1H-pyrazol-1-yl)-1,3,5-triazin-2-amine (8), Orange powder, yield $1.62 \mathrm{~g}$ (38\%); m.p. 207-208 ${ }^{\circ} \mathrm{C}$; IR (KBr) $v_{\max }\left(\mathrm{cm}^{-1}\right)$ : 3208, 2923, 2855, 1672, $1605,1533,1439,1376,1330,1261,1237,1155,813 ;{ }^{1} \mathrm{H}-\mathrm{NMR}\left(200 \mathrm{MHz}, \mathrm{DMSO}-d_{6}\right) \delta$ (ppm): $1.53(\mathrm{~s}, 6 \mathrm{H}$, $\left.2 \times \mathrm{xH}_{3}\right), 1.61\left(\mathrm{~s}, 3 \mathrm{H}, \mathrm{CH}_{3}\right), 3.76\left(\mathrm{~s}, 2 \mathrm{H}, \mathrm{CH}_{2}\right), 7.13$ (br.s, $\left.2 \mathrm{H}, \mathrm{NH}_{2}\right), 7.18(\mathrm{~d}, J=8.8 \mathrm{~Hz}, 1 \mathrm{H}, \mathrm{CH}), 7.66(\mathrm{dd}$, $\left.J_{1}=2.3 \mathrm{~Hz}, J_{2}=8.8 \mathrm{~Hz}, 1 \mathrm{H}, \mathrm{CH}\right), 7.98(\mathrm{~d}, J=2.3 \mathrm{~Hz}, 1 \mathrm{H}, \mathrm{CH}), 8.50(\mathrm{~s}, 1 \mathrm{H}, \mathrm{CH}), 10.82(\mathrm{~s}, 1 \mathrm{H}, \mathrm{NH})$. Anal. calcd for $\mathrm{C}_{18} \mathrm{H}_{18} \mathrm{BrN}_{7} \mathrm{O}$ (428.29): $\mathrm{C}, 50.48 ; \mathrm{H}, 4.24 ; \mathrm{N}, 22.89$. Found: $\mathrm{C}, 50.42 ; \mathrm{H}, 4.12 ; \mathrm{N}, 22.84$. 
4-(2-Imino-6-methyl-2H-chromen-3-yl)-6-(3,5,5-trimethyl-4,5-dihydro-1H-pyrazol-1-yl)-1,3,5-triazin-2-amine (9), Yellow powder, yield $1.12 \mathrm{~g}(31 \%)$; m.p. $172-173{ }^{\circ} \mathrm{C}$; IR (KBr) $v_{\max }\left(\mathrm{cm}^{-1}\right)$ : 3448, 3209, 1649, 1522, 1458, 1399, 1379, 1339, 810, 608; ${ }^{1} \mathrm{H}-\mathrm{NMR}\left(500 \mathrm{MHz}, \mathrm{DMSO}-d_{6}\right) \delta(\mathrm{ppm}): 1.64\left(\mathrm{~s}, 6 \mathrm{H}, 2 \mathrm{xCH}_{3}\right), 2.02(\mathrm{~s}$, $\left.3 \mathrm{H}, \mathrm{CH}_{3}\right), 2.34\left(\mathrm{~s}, 3 \mathrm{H}, \mathrm{CH}_{3}\right), 2.89\left(\mathrm{~s}, 2 \mathrm{H}, \mathrm{CH}_{2}\right), 7.12(\mathrm{~d}, J=8.2 \mathrm{~Hz}, 1 \mathrm{H}, \mathrm{CH}), 7.24$ (br.s, $\left.2 \mathrm{H}, \mathrm{NH}_{2}\right), 7.36(\mathrm{~d}$, $J=8.2 \mathrm{~Hz}, 1 \mathrm{H}, \mathrm{CH}), 7.43$ (s, 1H, CH), 8.36 (br.s, $0.5 \mathrm{H}, \mathrm{CH}), 8.40$ (br.s, $0.5 \mathrm{H}, \mathrm{CH}$ ); 10.63 (br.s, $0.5 \mathrm{H}, \mathrm{NH}$ ), 11.00 (br.s, 0.5H, NH). Anal. calcd for $\mathrm{C}_{19} \mathrm{H}_{21} \mathrm{~N}_{7} \mathrm{O}$ (363.42): C, 62.79; $\mathrm{H}, 5.82 ; \mathrm{N}, 26.98$. Found: $\mathrm{C}, 62.68$; $\mathrm{H}, 5.78 ; \mathrm{N}, 26.92$.

4-(2-Imino-2H-chromen-3-yl)-6-(4-phenylpiperazin-1-yl)-1,3,5-triazin-2-amine (10), Yellow powder, yield $1.07 \mathrm{~g}(27 \%)$; m.p. $193-194{ }^{\circ} \mathrm{C}$; IR (KBr) $v_{\max }\left(\mathrm{cm}^{-1}\right)$ : 3475, 3295, 3178, 3061, 2851, 1655, 1615, 1600, 1526, 1444, 1398, 1375, 1286, 1233, 1040, 1007, 938, 814, 754; ${ }^{1} \mathrm{H}-\mathrm{NMR}$ (200 MHz, DMSO- $\left.d_{6}\right) \delta$ (ppm): 3.15-3.30 $\left(\mathrm{m}, 4 \mathrm{H}, 2 \times \mathrm{CH}_{2}\right), 3.85-4.05\left(\mathrm{~m}, 4 \mathrm{H}, 2 \times \mathrm{CH}_{2}\right), 6.82(\mathrm{t}, 1 \mathrm{H}, \mathrm{CH}), 7.00(\mathrm{~d}, J=8.1 \mathrm{~Hz}, 2 \mathrm{H}, 2 \times \mathrm{CH}), 7.15-7.40$ $\left(\mathrm{m}, 6 \mathrm{H}, 4 \times \mathrm{CH}+\mathrm{NH}_{2}\right), 7.50-7.60(\mathrm{~m}, 1 \mathrm{H}, \mathrm{CH}), 7.68(\mathrm{~d}, J=7.4 \mathrm{~Hz}, 1 \mathrm{H}, \mathrm{CH}), 8.57(\mathrm{~s}, 1 \mathrm{H}, \mathrm{CH}), 10.72(\mathrm{~s}$, $1 \mathrm{H}, \mathrm{NH}) ;{ }^{13} \mathrm{C}$ NMR $\left(50 \mathrm{MHz}, \mathrm{DMSO}-d_{6}\right) \delta$ (ppm): 41.06 (2 overlapping signals), 48.59 (2 overlapping signals), 115.46, 116.21 (2 overlapping signals), 118.76, 119.58, 121.38, 123.62, 129.26 (2 overlapping signals), $129.54,133.22,137.91,151.20,153.85,159.18,164.10,166.31,167.94$. Anal. calcd for $\mathrm{C}_{22} \mathrm{H}_{21} \mathrm{~N}_{7} \mathrm{O}$ (399.45): C, 66.15; H, 5.30; N, 24.55. Found: C, 66.09; H, 5.26; N, 24.48.

4-[7-(Diethylamino)-2-imino-2H-chromen-3-yl]-6-(4-phenylpiperazin-1-yl)-1,3,5-triazin-2-amine (11), Orange powder, yield $2.54 \mathrm{~g}(54 \%) ; \mathrm{m} . p .158-159^{\circ} \mathrm{C}$; IR (KBr) $\nu_{\max }\left(\mathrm{cm}^{-1}\right): 3496,3392,3315,3252,3204,3054$, 2971, 2853, 1652, 1604, 1510, 1439, 1397, 1350, 1288, 1235, 1160, 1137, 1007, 815, 756, 690; ${ }^{1} \mathrm{H}-\mathrm{NMR}(500$ MHz, DMSO- $\left.d_{6}\right) \delta(\mathrm{ppm}): 1.14\left(\mathrm{t}, 6 \mathrm{H}, 2 \mathrm{xCH}_{3}\right), 3.20-3.25\left(\mathrm{~m}, 4 \mathrm{H}, 2 \mathrm{xCH}_{2}\right), 3.44\left(\mathrm{q}, 4 \mathrm{H}, 2 \mathrm{xCH}_{2}\right), 3.85-4.00$ $\left(\mathrm{m}, 4 \mathrm{H}, 2 \mathrm{CH}_{2}\right), 6.41(\mathrm{~s}, 1 \mathrm{H}, \mathrm{CH}), 6.55(\mathrm{~d}, J=8.8 \mathrm{~Hz}, 1 \mathrm{H}, \mathrm{CH}), 6.83(\mathrm{t}, 1 \mathrm{H}, \mathrm{CH}), 6.95-7.05(\mathrm{~m}, 3 \mathrm{H}, 2 \times \mathrm{CH}$ $+\mathrm{NH}), 7.13$ (br.s, $1 \mathrm{H}, \mathrm{NH}), 7.25(\mathrm{t}, 2 \mathrm{H}, 2 \mathrm{xCH}), 7.40(\mathrm{~d}, J=8.8 \mathrm{~Hz}, 1 \mathrm{H}, \mathrm{CH}), 8.46(\mathrm{~s}, 1 \mathrm{H}, \mathrm{CH}), 10.49(\mathrm{~s}, 1 \mathrm{H}$, $\mathrm{NH}$ ). Anal. calcd for $\mathrm{C}_{26} \mathrm{H}_{30} \mathrm{~N}_{8} \mathrm{O}$ (470.57): $\mathrm{C}, 66.36 ; \mathrm{H}, 6.43 ; \mathrm{N}, 23.81$. Found: $\mathrm{C}, 66.28 ; \mathrm{H}, 6.41 ; \mathrm{N}, 23.78$.

4-(6-Chloro-2-imino-2H-chromen-3-yl)-6-(4-phenylpiperazin-1-yl)-1,3,5-triazin-2-amine (12), Dark yellow powder, yield $1.43 \mathrm{~g}(33 \%) ; \mathrm{m} . p .196-197^{\circ} \mathrm{C}$; IR (KBr) $v_{\max }\left(\mathrm{cm}^{-1}\right): 3480,3389,3289,3195,3058,2908$, $2855,1653,1596,1521,1440,1394,1290,1230,1008,938,813,758,691 ;{ }^{1} \mathrm{H}-\mathrm{NMR}\left(500 \mathrm{MHz}\right.$, DMSO- $\left.d_{6}\right) \delta$ (ppm): $3.18-3.28\left(\mathrm{~m}, 4 \mathrm{H}, 2 \times \mathrm{CH}_{2}\right), 3.85-4.05\left(\mathrm{~m}, 4 \mathrm{H}, 2 \times \mathrm{CH}_{2}\right), 6.80-6.85(\mathrm{~m}, 1 \mathrm{H}, \mathrm{CH}), 7.02(\mathrm{~d}, J=7.8 \mathrm{~Hz}$, $2 \mathrm{H}, 2 \times \mathrm{CH}), 7.20-7.30(\mathrm{~m}, 4 \mathrm{H}, 3 \times \mathrm{CH}+\mathrm{NH}), 7.34$ (br.s, $1 \mathrm{H}, \mathrm{NH}), 7.57\left(\mathrm{dd}, J_{1}=2.0 \mathrm{~Hz}, J_{2}=8.8 \mathrm{~Hz}, 1 \mathrm{H}\right.$, $\mathrm{CH}), 7.86(\mathrm{~s}, 1 \mathrm{H}, \mathrm{CH}), 8.56(\mathrm{~s}, 1 \mathrm{H}, \mathrm{CH}), 10.81(\mathrm{~s}, 1 \mathrm{H}, \mathrm{NH})$. Anal. calcd for $\mathrm{C}_{22} \mathrm{H}_{20} \mathrm{ClN}_{7} \mathrm{O}$ (433.89): $\mathrm{C}$, $60.90 ; \mathrm{H}, 4.65 ; \mathrm{N}, 22.60$. Found: C, 60.82; H, 4.62; N, 22.51.

\subsection{Synthesis of 2H-chromen-3-yl-1,3,5-triazine Derivatives 13 and $\mathbf{1 4}$ (General Procedure)}

An appropriate amount of 2-imino-2H-chromen-3-yl-1,3,5-triazine derivative 10 or 12 (1.5 mmol) was dissolved in DMF containing $10 \%$ water $(2-4 \mathrm{~mL})$. The mixture was slowly heated with stirring to boiling for $10 \mathrm{~min}$, before being cooled to ambient temperature $\left(20-22{ }^{\circ} \mathrm{C}\right)$. Stirring was continued at room temperature $\left(20-22^{\circ} \mathrm{C}\right)$ and crushed ice was added until a precipitate was formed. The product was filtered, washed with water, dried and crystallized from DMF.

3-[4-Amino-6-(4-phenylpiperazin-1-yl)-1,3,5-triazin-2-yl]-2H-chromen-2-one (13), Light yellow powder, yield $0.46 \mathrm{~g}(77 \%)$; m.p. $266-267^{\circ} \mathrm{C}$; IR (KBr) $v_{\max }\left(\mathrm{cm}^{-1}\right)$ : 3464, 3325, 3165, 3067, 2974, 2833, 1735, 1663, $1628,1609,1557,1524,1504,1473,1442,1375,1291,1232,979,816,749 ;{ }^{1} \mathrm{H}-\mathrm{NMR}$ (500 MHz, DMSO- $d_{6}$ ) $\delta$ (ppm): 3.16-3.24 (m, 4H, 2xCH $\mathrm{CH}_{2}, 3.85-3.99\left(\mathrm{~m}, 4 \mathrm{H}, 2 \mathrm{CCH}_{2}\right), 6.83(\mathrm{t}, 1 \mathrm{H}, \mathrm{CH}), 7.01(\mathrm{~d}, J=8.3 \mathrm{~Hz}$, $2 \mathrm{H}, 2 \times \mathrm{CH}), 7.06$ (br.s, $1 \mathrm{H}, \mathrm{NH}), 7.13$ (br.s, $1 \mathrm{H}, \mathrm{NH}), 7.25(\mathrm{t}, 2 \mathrm{H}, 2 \mathrm{xCH}), 7.41(\mathrm{t}, 1 \mathrm{H}, \mathrm{CH}), 7.46(\mathrm{~d}, J=$ $8.3 \mathrm{~Hz}, 1 \mathrm{H}, \mathrm{CH}), 7.70(\mathrm{t}, 1 \mathrm{H}, \mathrm{CH}), 7.88(\mathrm{~d}, \mathrm{~J}=6.8 \mathrm{~Hz}, 1 \mathrm{H}, \mathrm{CH}), 8.55(\mathrm{~s}, 1 \mathrm{H}, \mathrm{CH}) ;{ }^{13} \mathrm{C}-\mathrm{NMR}(50 \mathrm{MHz}$, DMSO- $\left.\mathrm{d}_{6}\right) \delta$ (ppm): 42.78 (2 overlapping signals), 48.62 (2 overlapping signals), 116.21 (2 overlapping signals), 116.27, 118.76, 119.57, 124.93, 125.56, 129.25 (2 overlapping signals), 129.68, 133.25, 144.41, 151.25, 154.13, 157.50, 164.73, 167.12, 168.95. Anal. calcd for $\mathrm{C}_{22} \mathrm{H}_{20} \mathrm{~N}_{6} \mathrm{O}_{2}$ (400.43): $\mathrm{C}, 65.99 ; \mathrm{H}, 5.03 ; \mathrm{N}$, 20.99. Found: C, 65.79; H, 4.92; N, 20.91. 
3-[4-Amino-6-(4-phenylpiperazin-1-yl)-1,3,5-triazin-2-yl]-6-chloro-2H-chromen-2-one (14), Yellow powder, yield $0.48 \mathrm{~g}(74 \%)$; m.p. $245-246^{\circ} \mathrm{C}$; IR $(\mathrm{KBr}) v_{\max }\left(\mathrm{cm}^{-1}\right)$ : 3482, 3314, 3220, 2988, 2948, 2908, 2850, $1735,1645,1595,1569,1555,1529,1471,1442,1373,1288,1233,1045,946,827,814 ;{ }^{1} \mathrm{H}-\mathrm{NMR}(200 \mathrm{MHz}$, DMSO- $\left.d_{6}\right) \delta(\mathrm{ppm}): 3.05-3.45\left(\mathrm{~m}, 4 \mathrm{H}, 2 \mathrm{xCH}_{2}\right), 3.75-4.05\left(\mathrm{~m}, 4 \mathrm{H}, 2 \mathrm{xCH}_{2}\right), 6.81(\mathrm{t}, 1 \mathrm{H}, \mathrm{CH}), 6.90-7.14$ $(\mathrm{m}, 3 \mathrm{H}, 2 \mathrm{xCH}+\mathrm{NH}), 7.15-7.30(\mathrm{~m}, 2 \mathrm{H}, \mathrm{CH}+\mathrm{NH}), 7.35-7.55(\mathrm{~m}, 2 \mathrm{H}, 2 \mathrm{xCH}), 7.67(\mathrm{t}, 1 \mathrm{H}, \mathrm{CH}), 7.87$ $(\mathrm{d}, J=7.0 \mathrm{~Hz}, 1 \mathrm{H}, \mathrm{CH}), 8.54(\mathrm{~s}, 1 \mathrm{H}, \mathrm{CH})$. Anal. calcd for $\mathrm{C}_{22} \mathrm{H}_{19} \mathrm{ClN}_{6} \mathrm{O}_{2}(434.88): \mathrm{C}, 60.76 ; \mathrm{H}, 4.40 ; \mathrm{N}$, 19.32. Found: C, 60.68; H, 4.36; N, 19.28 .

\section{Conclusions}

The results of the biological studies indicate that hybrid compounds 5-14 have rather weak cytotoxic properties. However, significant antiproliferative potency is associated with a diethylamino substituent at the position 7 of the coumarin ring (compounds 6 and 11). Importantly, compound 11 with a bulky 4-phenylpiperazine moiety installed at the position $6^{\prime}$ of the triazine ring showed similar potency to cisplatin against several of the cell lines. It is too early to speculate on the mechanism of action of the compound 11. However, it is well known that coumarins are minor groove binders and exhibit the intercalative mode of binding properties with DNA [75,76]. Therefore, the presence of diethylamino group may increase the efficiency of the intercalative binding due to the extra non-covalent force between the substituent and DNA grooves. The most potent 2,4-diamino-1,3,5-triazine-imino-coumarin 11 may serve as a lead structure for further development of new antitumor drugs. Thus, the hybrid molecule composed of 2,4-diamino-1,3,5-triazine and 2 -iminocoumarin was proven to be a promising heterocyclic scaffold for the construction of novel cytotoxic compounds. The syntheses of analogues containing lipophilic substituents at the position $6^{\prime}$ of the triazine ring and electron-donating substituents at the positions 5, 6, 7 or 8 of the imino-coumarin moiety, along with quantitative structure-activity relationship (QSAR) studies, are planned.

Author Contributions: Conceived and designed the project: F.S. Performed chemical experiments: A.M. Designed the biological tests: P.J.B. Performed biological tests: A.M. Performed molecular modeling studies: J.S. Wrote the paper: F.S., Ł.B., P.J.B. All authors read and approved the final manuscript.

Acknowledgments: A.M. thanks the European Union student exchange program Erasmus for financial support (maintenance and accommodation).

Conflicts of Interest: The authors declare no conflict of interest.

\section{References}

1. Decker, M. Hybrid Molecules for Drug Development; Elsevier Ltd.: New York, NY, USA, 2017.

2. Vance, D.; Shah, M.; Joshi, A.; Kane, R.S. Polyvalency: A promising strategy for drug design. Biotechnol. Bioeng. 2008, 101, 429-434. [CrossRef] [PubMed]

3. Mishra, S.S.; Singh, P. Hybrid molecules: The privileged scaffolds for various pharmaceuticals. Eur. J. Med. Chem. 2016, 124, 500-536.

4. Solomon, V.R.; Hu, C.; Lee, H. Hybrid pharmacophore design and synthesis of isatin-benzothiazole analogs for their anti-breast cancer activity. Bioorg. Med. Chem. 2009, 17, 7585-7592. [CrossRef] [PubMed]

5. Kamal, A.; Reddy, K.S.; Khan, M.N.A.; Shetti, R.V.C.R.N.C.; Ramaiah, M.J.; Pushpavalli, S.N.C.V.L.; Srinivas, C.; Pal-Bhadra, M.; Chourasia, M.; Sastry, G.N.; et al. Synthesis, DNA-binding ability and anticancer activity of benzothiazole/benzoxazole-pyrrolo[2,1-c][1,4]benzodiazepine conjugates. Bioorg. Med. Chem. 2010, 18, 4747-4761. [CrossRef] [PubMed]

6. Kelly, P.M.; Keely, N.O.; Bright, S.A.; Yassin, B.; Ana, G.; Fayne, D.; Zisterer, D.M.; Meegan, M.J. Novel selective estrogen receptor ligand conjugates incorporating endoxifen-combretastatin and cyclofenil-combretastatin hybrid scaffolds: Synthesis and biochemical evaluation. Molecules 2017, 22, 1440. [CrossRef] [PubMed]

7. Lödige, M.; Hiersch, L. Design and synthesis of novel hybrid molecules against malaria. Int. J. Med. Chem. 2015, 2015, 458319. [CrossRef] [PubMed] 
8. Spilovska, K.; Korabecny, J.; Sepsova, V.; Jun, D.; Hrabinova, M.; Jost, P.; Muckova, L.; Soukup, O.; Janockova, J.; Kucera, T.; et al. Novel tacrine-scutellarin hybrids as multipotent anti-Alzheimer's agents: Design, synthesis and biological evaluation. Molecules 2017, 22, 1006. [CrossRef] [PubMed]

9. Tang, C.; Li, C.; Zhang, S.; Hu, Z.; Wu, J.; Dong, C.; Huang, J.; Zhou, H.-B. Novel Bioactive Hybrid Compound Dual Targeting Estrogen Receptor and Histone Deacetylase for the Treatment of Breast Cancer. J. Med. Chem. 2015, 58, 4550-4572. [CrossRef] [PubMed]

10. Theoduloz, C.; Delporte, C.; Valenzuela-Barra, G.; Silva, X.; Cádiz, S.; Bustamante, F.; Pertino, M.W.; Scheda-Hirschmann, G. Topical anti-inflammatory activity of new hybrid molecules of terpenes and synthetic drugs. Molecules 2015, 20, 11219-11235. [CrossRef] [PubMed]

11. Rodríguez-Franco, M.I.; Fernández-Bachiller, M.I.; Pérez, C.; Hernández-Ledesma, B.; Bartolomé, B. Novel tacrine-melatonin hybrids as dual-acting drugs for Alzheimer disease, with improved acetylcholinesterase inhibitory and antioxidant properties. J. Med. Chem. 2006, 49, 459-462. [CrossRef] [PubMed]

12. Fernández-Bachiller, M.I.; Pérez, C.; Campillo, N.E.; Páez, A.; González-Muñoz, G.C.; Usán, P.; García-Palomero, E.; López, M.G.; Villarroya, M.; García, A.G.; et al. Tacrine-melatonin hybrids as multifunctional agents for Alzheimer's disease, with cholinergic, antioxidant, and neuroprotective properties. ChemMedChem 2009, 4, 828-841. [CrossRef] [PubMed]

13. Liu, K.; Zhang, D.; Chojnacki, J.; Du, Y.; Fu, H.; Grant, S.; Zhang, S. Design and biological characterization of hybrid compounds of curcumin and thalidomide for multiple myeloma. Org. Biomol. Chem. 2013, 11, 4757-4763. [CrossRef] [PubMed]

14. Decker, M. Hybrid molecules incorporating natural products: Applications in cancer therapy, neurodegenerative disorders and beyond. Curr. Med. Chem. 2011, 18, 1464-1475. [CrossRef] [PubMed]

15. Porwal, S.; Chauhan, S.S.; Chauhan, P.M.S.; Shakya, N.; Verma, A.; Gupta, S. Discovery of novel antileishmanial agents in an attempt to synthesize pentamidine-aplysinopsin hybrid molecule. J. Med. Chem. 2009, 52, 5793-5802. [CrossRef] [PubMed]

16. Pingaew, R.; Saekee, A.; Mandi, P.; Nantasenamat, C.; Prachayasittikul, S.; Ruchirawat, S.; Prachayasittikul, V. Synthesis, biological evaluation and molecular docking of novel chalcone-coumarin hybrids as anticancer and antimalarial agents. Eur. J. Med. Chem. 2014, 85, 65-76. [CrossRef] [PubMed]

17. Singla, P.; Luxami, V.; Paul, K. Triazine as a promising scaffold for its versatile biological behavior. Eur. J. Med. Chem. 2015, 102, 39-57. [CrossRef] [PubMed]

18. Cascioferro, S.; Parrino, B.; Spanò, V.; Carbone, A.; Montalbano, A.; Barraja, P.; Diana, P.; Cirrincione, G. 1,3,5-Triazines: A promising scaffold for anticancer drugs. Eur. J. Med. Chem. 2017, 142, 523-549. [CrossRef] [PubMed]

19. Lee, C.R.; Faulds, D. Altretamine: A review of its pharmacodynamic and pharmacokinetic properties, and therapeutic potential in cancer chemotherapy. Drugs 1995, 49, 932-953. [CrossRef] [PubMed]

20. Coley, H.M.; Jarman, M.; Sargent, J.M.; Kubota, T.; Lee, N.C.; Goddard, P.M.; Elgie, A.W.; Williamson, C.; Taylor, C.G.; Judson, I.R. The activity of $N$-(hydroxymethyl) melamines in fresh human ovarian tumor cells and xenografts. Anticancer Res. 1996, 16, 1851-1855. [PubMed]

21. Nozaki, S.; Maeda, M.; Tsuda, H.; Sledge, G.W., Jr. Inhibition of breast cancer regrowth and pulmonary metastasis in nude mice by anti-gastric ulcer agent, irsogladine. Breast Cancer Res. Treat. 2004, 83, 195-199. [CrossRef] [PubMed]

22. Sun, D.; Melman, G.; LeTourneau, N.J.; Hays, A.M.; Melman, A. Synthesis and antiproliferating activity of iron chelators of hydroxyamino-1,3,5-triazine family. Bioorg. Med. Chem. Lett. 2010, 20, 458-460. [CrossRef] [PubMed]

23. Arya, K.; Dandia, A. Synthesis and cytotoxic activity of trisubstituted-1,3,5-triazines. Bioorg. Med. Chem. Lett. 2007, 17, 3298-3304. [CrossRef] [PubMed]

24. Shanmugam, M.; Narayanan, K.; Prasad, K.H.; Karthikeyan, D.; Chandrasekaran, L.; Atchudan, R.; Chidambaranathan, V. Synthesis, characterization, antiproliferative and apoptosis inducing effects of novel s-triazine derivatives. New J. Chem. 2018, 42, 1698-1714. [CrossRef]

25. Srivastava, J.K.; Pillai, G.G.; Bhat, H.R.; Verma, A.; Singh, U.P. Design and discovery of novel monastrol-1,3,5-triazines as potent anti-breast cancer agent via attenuating epidermal growth factor receptor tyrosine kinase. Sci. Rep. 2017, 7, 5851. [CrossRef] [PubMed] 
26. Kumar, R.; Gupta, L.; Pal, P.; Khan, S.; Singh, N.; Katiyar, S.B.; Meena, S.; Sarkar, J.; Sinha, S.; Kanaujiya, J.K.; et al. Synthesis and cytotoxicity evaluation of (tetrahydro- $\beta$-carboline)-1,3,5-triazine hybrids as anticancer agents. Eur. J. Med. Chem. 2010, 45, 2265-2276. [CrossRef] [PubMed]

27. Moreau, D.; Jacquot, C.; Tsita, P.; Chinou, I.; Tomasoni, C.; Juge, M.; Antoniadou-Vyza, E.; Martignat, L.; Pineau, A.; Roussakis, C. Original triazine inductor of new specific molecular targets, with antitumor activity against nonsmall cell lung cancer. Int. J. Cancer 2008, 123, 2676-2683. [CrossRef] [PubMed]

28. Riou, J.F.; Guittat, L.; Mailliet, P.; Laoui, A.; Renou, E.; Petitgenet, O.; Mégnin-Chanet, F.; Hélène, C.; Mergny, J.L. Cell senescence and telomere shortening induced by a new series of specific G-quadruplex DNA ligands. Proc. Natl. Acad. Sci. USA 2002, 99, 2672-2677. [CrossRef] [PubMed]

29. Popowycz, F.; Schneider, C.; DeBonis, S.; Skoufias, D.A.; Kozielski, F.; Galmarini, C.M.; Joseph, B. Synthesis and antiproliferative evaluation of pyrazolo[1,5-a]-1,3,5-triazine myoseverin derivatives. Bioorg. Med. Chem. 2009, 17, 3471-3478. [CrossRef] [PubMed]

30. Moon, H.-S.; Jacobson, E.M.; Khersonsky, S.M.; Luzung, M.R.; Walsh, D.P.; Xiong, W.; Lee, J.W.; Parikh, P.B.; Lam, J.C.; Kang, T.-W.; et al. A novel microtubule destabilizing entity from orthogonal synthesis of triazine library and zebrafish embryo screening. J. Am. Chem. Soc. 2002, 124, 11608-11609. [CrossRef] [PubMed]

31. Baindur, N.; Chadha, N.; Brandt, B.M.; Asgari, D.; Patch, R.J.; Schalk-Hihi, C.; Carver, T.E.; Petrounia, I.P.; Baumann, C.A.; Ott, H.; et al. 2-Hydroxy-4,6-diamino-[1,3,5]triazines: A novel class of VEGF-R2 (KDR) tyrosine kinase inhibitors. J. Med. Chem. 2005, 48, 1717-1720. [CrossRef] [PubMed]

32. Hodous, B.L.; Geuns-Meyer, S.D.; Hughes, P.E.; Albrecht, B.K.; Bellon, S.; Bready, J.; Caenepeel, S.; Cee, V.J.; Chaffee, S.C.; Coxon, A.; et al. Evolution of a highly selective and potent 2-(pyridin-2-yl)-1,3,5-triazine Tie-2 kinase inhibitor. J. Med. Chem. 2007, 50, 611-626. [CrossRef] [PubMed]

33. Kuo, G.H.; Deangelis, A.; Emanuel, S.; Wang, A.; Zhang, Y.; Connolly, P.J.; Chen, X.; Gruninger, R.H.; Rugg, C.; Fuentes-Pesquera, A.; et al. Synthesis and identification of [1,3,5]triazine-pyridine biheteroaryl as a novel series of potent cyclin-dependent kinase inhibitors. J. Med. Chem. 2005, 48, 4535-4546. [CrossRef] [PubMed]

34. Nie, Z.; Perretta, C.; Erickson, P.; Margosiak, S.; Lu, J.; Averill, A.; Almassy, R.; Chu, S. Structure-based design and synthesis of novel macrocyclic pyrazolo[1,5- $a][1,3,5]$ triazine compounds as potent inhibitors of protein kinase CK2 and their anticancer activities. Bioorg. Med. Chem. Lett. 2008, 18, 619-623. [CrossRef] [PubMed]

35. Jain, A.K.; Veerasamy, R.; Vaidya, A.; Mourya, V.; Agrawal, R.K. QSAR analysis of some novel sulfonamides incorporating 1,3,5-triazine derivatives as carbonic anhydrase inhibitors. Med. Chem. Res. 2010, 19, 1191-1202. [CrossRef]

36. Garaj, V.; Puccetti, L.; Fasolis, G.; Winum, J.-Y.; Montero, J.-L.; Scozzafava, A.; Vullo, D.; Innocenti, A.; Supuran, C.T. Carbonic anhydrase inhibitors: Novel sulfonamides incorporating 1,3,5-triazine moieties as inhibitors of the cytosolic and tumour-associated carbonic anhydrase isozymes I, II and IX. Bioorg. Med. Chem. Lett. 2005, 15, 3102-3108. [CrossRef] [PubMed]

37. Saluja, A.K.; Tiwari, M.; Vullo, D.; Supuran, C.T. Substituted benzene sulfonamides incorporating 1,3,5-triazinyl moieties potently inhibit human carbonic anhydrases II, IX and XII. Bioorg. Med. Chem. Lett. 2014, 24, 1310-1314. [CrossRef] [PubMed]

38. Detsi, A.; Kontogiorgis, C.; Hadjipavlou-Litina, D. Coumarin derivatives: An updated patent review (2015-2016). Expert Opin. Ther. Pat. 2017, 27, 1201-1226. [CrossRef] [PubMed]

39. Nofal, Z.M.; El-Zahar, M.I.; Abd El-Karim, S.S. Novel coumarin derivatives with expected biological activity. Molecules 2000, 5, 99-113. [CrossRef]

40. Borges, F.; Roleira, F.; Milhazes, N.; Santana, L.; Uriarte, E. Simple coumarins and analogues in medicinal chemistry: Occurrence, synthesis and biological activity. Curr. Med. Chem. 2005, 12, 887-916. [CrossRef] [PubMed]

41. Reddy, N.S.; Mallireddigari, M.R.; Cosenza, S.; Gumireddy, K.; Bell, S.C.; Reddy, E.P.; Reddy, M.V.R. Synthesis of new coumarin 3-(N-aryl) sulfonamides and their anticancer activity. Bioorg. Med. Chem. Lett. 2004, 14, 4093-4097. [CrossRef] [PubMed]

42. Belluti, F.; Fontana, G.; Dal Bo, L.; Carenini, N.; Giommarelli, C.; Zunino, F. Design, synthesis and anticancer activities of stilbene-coumarin hybrid compounds: Identification of novel proapoptotic agents. Bioorg. Med. Chem. 2010, 18, 3543-3550. [CrossRef] [PubMed] 
43. Finn, G.J.; Creaven, B.; Egan, D.A. Study of the in vitro cytotoxic potential of natural and synthetic coumarin derivatives using human normal and neoplastic skin cell lines. Melanoma Res. 2001, 11, 461-467. [CrossRef] [PubMed]

44. Kostova, I. Synthetic and natural coumarins as cytotoxic agents. Curr. Med. Chem. 2005, 5, 29-46. [CrossRef]

45. Thakur, A.; Singla, R.; Jaitak, V. Coumarins as anticancer agents: A review on synthetic strategies, mechanism of action and SAR studies. Eur. J. Med. Chem. 2015, 101, 476-495. [CrossRef] [PubMed]

46. Donnely, A.C.; Mays, J.R.; Burlison, J.A.; Nelson, J.T.; Vielhauer, G.; Holzbeierlein, J.; Blagg, B.S.J. The design, synthesis, and evaluation of coumarin ring derivatives of the novobiocin scaffold that exhibit antiproliferative activity. J. Org. Chem. 2008, 73, 8901-8920. [CrossRef] [PubMed]

47. Lopez-Gonzales, J.S.; Prado-Garcia, H.; Aguilar-Cazares, D.; Molina-Guarneros, J.A.; Morales-Fuentes, J.; Mandoki, J.J. Apoptosis and cell cycle disturbances induced by coumarin and 7-hydroxycoumarin on human lung carcinoma cell lines. Lung Cancer 2004, 43, 275-283. [CrossRef] [PubMed]

48. Yim, D.; Singh, R.P.; Agarwal, C.; Lee, S.; Chi, H.; Agarwal, R. A novel anticancer agent, decursin, induces $\mathrm{G}_{1}$ arrest and apoptosis in human prostate carcinoma cells. Cancer Res. 2005, 65, 1035-1044. [PubMed]

49. Payne, S.L.; Rodriguez-Aristegui, S.; Bardos, J.; Cano, C.; Golding, B.T.; Hardcastle, I.R.; Peacock, M.; Parveen, N.; Griffin, R.J. Mapping the ATP-binding domain of DNA-dependent protein kinase (DNA-PK) with coumarin- and isocoumarin-derived inhibitors. Bioorg. Med. Chem. Lett. 2010, 20, 3649-3653. [CrossRef] [PubMed]

50. Han, S.; Zhou, V.; Pan, S.; Liu, Y.; Hornsby, M.; McMullan, D.; Klock, H.E.; Haugen, J.; Lesley, S.A.; Gray, N.; et al. Identification of coumarin derivatives as a novel class of allosteric MEK1 inhibitors. Bioorg. Med. Chem. Lett. 2005, 15, 5467-5473. [CrossRef] [PubMed]

51. Starčević, S. .; Brožič, P.; Turk, S.; Cesar, J.; Rižner, T.L.; Gobec, S. Synthesis and biological evaluation of (6- and 7-phenyl) coumarin derivatives as selective nonsteroidal inhibitors of $17 \beta$-hydroxysteroid dehydrogenase type 1. J. Med. Chem. 2011, 54, 248-261. [CrossRef] [PubMed]

52. Maresca, A.; Temperini, C.; Vu, H.; Pham, N.B.; Poulsen, S.-A.; Scozzafava, A.; Quinn, R.J.; Supuran, C.T. Non-zinc mediated inhibition of carbonic anhydrases: Coumarins are a new class of suicide inhibitors. J. Am. Chem. Soc. 2009, 131, 3057-3062. [CrossRef] [PubMed]

53. Supuran, C.T. Carbonic anhydrase inhibitors. Bioorg. Med. Chem. Lett. 2010, 20, 3467-3474. [CrossRef] [PubMed]

54. Cao, D.; Liu, Y.; Yan, W.; Wang, C.; Bai, P.; Wang, T.; Tang, M.; Wang, X.; Yang, Z.; Ma, B.; et al. Design, synthesis, and evaluation of in vitro and in vivo anticancer activity of 4-substituted coumarins: A novel class of potent tubulin polymerization inhibitors. J. Med. Chem. 2016, 59, 5721-5739. [CrossRef] [PubMed]

55. Ganina, O.G.; Daras, E.; Bourgarel-Rey, V.; Peyrot, V.; Andresyuk, A.N.; Finet, J.-P.; Fedorov, A.Y.; Beletskaya, I.P.; Combes, S. Synthesis and biological evaluation of polymethoxylated 4-heteroarylcoumarins as tubulin assembly inhibitor. Bioorg. Med. Chem. 2008, 16, 8806-8812. [CrossRef] [PubMed]

56. Kim, S.-N.; Kim, N.H.; Park, Y.S.; Kim, H.; Lee, S.; Wang, Q.; Kim, Y.K. 7-Diethylamino-3(2'-benzoxazolyl)coumarin is a novel microtubule inhibitor with antimitotic activity in multidrug resistant cancer cells. Biochem. Pharmacol. 2009, 77, 1773-1779. [CrossRef] [PubMed]

57. Lee, S.; Sivakumar, K.; Shin, W.-S.; Xie, F.; Wang, Q. Synthesis and anti-angiogenesis activity of coumarin derivatives. Bioorg. Med. Chem. Lett. 2006, 16, 4596-4599. [CrossRef] [PubMed]

58. O'Callaghan, C.N.; Conalty, M.L. Anticancer Agents XIII. Synthesis and antitumour activity of 2-iminochromene derivatives. Proc. R. Ir. Acad. Sect. B 1979, 79, 87-98.

59. Huang, C.-K.; Wu, F.-Y.; Ai, Y.-X. Polyhydroxylated 3-(N-phenyl) carbamoyl-2-iminochromene derivatives as potent inhibitors of tyrosine kinase p60-src. Bioorg. Med. Chem. Lett. 1995, 5, 2423-2428. [CrossRef]

60. Huang, C.-K. 2-Iminochromene Derivatives as Inhibitors of Protein Tyrosine Kinase; WO 96/40670 (PTC/US96/07295); Research Corporation Technologies, Inc.: Tucson, AZ, USA, 1996.

61. Burke, T.R.; Lim, B.; Marquez, V.E.; Li, Z.H.; Bolen, J.B.; Stefanova, I.; Horak, I.D. Bicyclic compounds as ring-constrained inhibitors of protein-tyrosine kinase p56 ${ }^{\mathrm{lk} 1}$. J. Med. Chem. 1993, 36, 425-432. [CrossRef] [PubMed]

62. Gill, R.K.; Kumari, J.; Bariwal, J. New 2-imino-2H-chromene-3(N-aryl)carboxamides as potential cytotoxic agents. Anti-Cancer Agents Med. Chem. 2017, 17, 85-92. [CrossRef]

63. Brzozowski, Z.; Saczewski, F.; Gdaniec, M. Synthesis, structural characterization and antitumor activity of novel 2,4-diamino-1,3,5-triazine derivatives. Eur. J. Med. Chem. 2000, 35, 1053-1064. [CrossRef] 
64. Brzozowski, Z.; Saczewski, F. Synthesis and antitumor activity of novel 2-amino-4-(3,5,5-trimethyl-2pyrazolino)-1,3,5-triazine derivatives. Eur. J. Med. Chem. 2002, 37, 709-720. [CrossRef]

65. Saczewski, F.; Bułakowska, A. Synthesis, structure and anticancer activity of novel alkenyl-1,3,5-triazine derivatives. Eur. J. Med. Chem. 2006, 41, 611-615. [CrossRef] [PubMed]

66. Saczewski, F.; Bułakowska, A.; Bednarski, P.; Grunert, R. Synthesis, structure and anticancer activity of novel 2,4-diamino-1,3,5-triazine derivatives. Eur. J. Med. Chem. 2006, 41, 219-225. [CrossRef] [PubMed]

67. Brzozowski, Z.; Kamiński, Z.; Kozakiewicz, I.; Angielski, S.; Rogulski, J. Synteza I właściwości hipoglikemizujące niektórych pochodnych N-(2-pirazolino-1-karbonimidoilo)-guanidyny. Acta Pol. Pharm. 1979, 36, 401-410. [PubMed]

68. Pomarnacka, E.; Bednarski, P.; Grunert, R.; Reszka, P. Synthesis and anticancer activity of novel 2-amino-4-(4-phenylpiperazino)-1,3,5-triazine derivatives. Acta Pol. Pharm. Drug Res. 2004, 61, 461-467.

69. Wavefunction Inc. Molecular Modelling Studies were Performed at ab Initio Level Using the Density Functional (B3LYP) Method with the 6-31G* Basis Set as Implemented into SPARTAN Program Version '08; Wavefunction Inc.: Irvine, CA, USA; Available online: www.wavefun.com (accessed on 25 June 2018).

70. Becke, A.D. Density-functional thermochemistry. III. The role of exact exchange. J. Chem. Phys. 1993, 98, 5648-5652. [CrossRef]

71. Tomasi, J.; Mennucci, B.; Cammi, R. Quantum mechanical continuum solvation models. Chem. Rev. 2005, 105, 2999-3094. [CrossRef] [PubMed]

72. Dryanska, V. An Efficient one-pot synthesis of 3-(2-benzothiazolyl)coumarins. Synth. Commun. 1987, 17, 203-209. [CrossRef]

73. Bracht, K.; Boubakari; Grünert, R.; Bednarski, J.P. Correlations between the activities of 19 antitumor agents and the intracellular glutathione concentrations in a panel of 14 human cancer cell lines: Comparisons with the National Cancer Institute data. Anticancer Drugs 2006, 11, 257-261.

74. Shapiro, S.L.; Parrino, V.A.; Freedman, L. Hypoglycemic agents. III. $\mathrm{N}^{1}$-alkyl- and aralkylbiguanides. J. Am. Chem. Soc. 1959, 81, 3728-3736. [CrossRef]

75. Chen, H.; Li, S.; Yao, Y.; Zhou, L.; Zhao, J.; Gu, Y.; Wang, K.; Li, X. Design, synthesis and anti-tumor activities of novel triphenylene-coumarin hybrids, and their interaction with Ct-DNA. Bioorg. Med. Chem. Lett. 2013, 23, 4785-4789. [CrossRef] [PubMed]

76. Sarwar, T.; Rehman, S.U.; Husain, M.A.; Ishiqi, H.M.; Tabish, M. Interaction of coumarin with calf thymus DNA: Deciphering the mode of binding by in vitro studies. Int. J. Biol. Macromol. 2015, 73, 9-16. [CrossRef] [PubMed]

Sample Availability: Samples of the compounds 5-14 are available from the authors.

(C) 2018 by the authors. Licensee MDPI, Basel, Switzerland. This article is an open access article distributed under the terms and conditions of the Creative Commons Attribution (CC BY) license (http:/ / creativecommons.org/licenses/by/4.0/). 